\title{
Shape Memory Alloys and Polymers for MEMS/NEMS Applications: Review on Recent Findings and Challenges in Design, Preparation, and Characterization
}

\author{
Ivo Stachiv ${ }^{1,2, *(\mathbb{D})}$, Eduardo Alarcon ${ }^{1}(\mathbb{D})$ and Miroslav Lamac ${ }^{1}$ \\ 1 Department of Functional Materials, Institute of Physics, Czech Academy of Sciences, Na Slovance 2, \\ 18221 Prague, Czech Republic; alarcon@fzu.cz (E.A.); lamac@fzu.cz (M.L.) \\ 2 Research and Development Department, Drážní revize s.r.o., Místecká \\ 1120/103, 70300 Ostrava-Vitkovice, Czech Republic \\ * Correspondence: stachiv@fzu.cz; Tel.: +420-266-05-2428
}

Citation: Stachiv, I.; Alarcon, E.; Lamac, M. Shape Memory Alloys and Polymers for MEMS/NEMS Applications: Review on Recent Findings and Challenges in Design, Preparation, and Characterization. Metals 2021, 11, 415. https:// doi.org/10.3390/met11030415

Academic Editor: Ryosuke Kainuma

Received: 2 February 2021

Accepted: 25 February 2021

Published: 3 March 2021

Publisher's Note: MDPI stays neutral with regard to jurisdictional claims in published maps and institutional affiliations.

Copyright: (c) 2021 by the authors. Licensee MDPI, Basel, Switzerland. This article is an open access article distributed under the terms and conditions of the Creative Commons Attribution (CC BY) license (https:/ / creativecommons.org/licenses/by/ $4.0 /)$.

\begin{abstract}
Rapid progress in material science and nanotechnology has led to the development of the shape memory alloys (SMA) and the shape memory polymers (SMP) based functional multilayered structures that, due to their capability to achieve the properties not feasible by most natural materials, have attracted a significant attention from the scientific community. These shape memory materials can sustain large deformations, which can be recovered once the appropriate value of an external stimulus is applied. Moreover, the SMAs and SMPs can be reprogrammed to meet several desired functional properties. As a result, SMAs and SMPs multilayered structures benefit from the unprecedented physical and material properties such as the shape memory effect, superelasticity, large displacement actuation, changeable mechanical properties, and the high energy density. They hold promises in the design of advanced functional micro- and nano-electro-mechanical systems (MEMS/NEMS). In this review, we discuss the recent understanding and progress in the fields of the SMAs and SMPs. Particular attention will be given to the existing challenges, critical issues, limitations, and achievements in the preparation and characterization of the SMPs and NiTi-based SMAs thin films, and their heterostructures for MEMS/NEMS applications including both experimental and computational approaches. Examples of the recent MEMS/NEMS devices utilizing the unique properties of SMAs and SMPs such as micropumps, microsensors or tunable metamaterial resonators are highlighted. In addition, we also introduce the prospective future research directions in the fields of SMAs and SMPs for the nanotechnology applications.
\end{abstract}

Keywords: shape memory alloy; shape memory polymer; functional structures; thin film; $\mathrm{NiMn}_{2} \mathrm{Ga}$; phase transformation; MEMS; NEMS; functional devices; multilayered structures.

\section{Introduction}

Recent advances in material science and nanotechnology have enabled to develop the micro and nanoscale structures for a variety of applications. For example, they are used for the ultrasensitive identification of added mass [1,2], fluid viscosity [3], as well as for the infrared sensors [4], non-destructive characterization of the material properties $[5,6]$, or implement in the 2D tunable resonators [7], solar cells with enhanced efficiency [8] and the energy harvesting devices [9]. Recently, the investigation of the network behavior by the non-linear oscillators has been also suggested [10]. To ensure these structures can achieve the extraordinary functional properties (e.g., the ultrahigh sensitivity to the given external stimulus), they are usually made of either the novel nanomaterials such as the single-/multiwalled carbon nanotube [11], graphene [12] and the $\mathrm{MoS}_{2}$ [13] or the multiple material layers, where at least one layer contains (or is made of) a functional material [14-16]. Note that many functional materials like the piezoelectric [17], magnetostrictive [18], photo-sensitive [19] ones or the shape memory polymers (SMPs) [20] 
and the shape memory alloys (SMAs) [21] have been already discovered and extensively studied. Each functional material has one or more particular modifiable properties (e.g., shape, volume, electric conductivity, the Young's modulus or Poison's ratio) that can be altered by the different external stimuli like changes in light and temperature, or by applying external magnetic, mechanical or electrical fields. These functional properties make them highly attractive in the design of advanced micro-/nano-electro-mechanical systems (MEMS/NEMS) [22-24]. One of the most successful application of functional MEMS can be found in energy harvesting devices. Up to date, the piezoelectric materials that are capable of converting the mechanical energy into the electrical energy, have been the most commonly used [25], although successful prototypes using other functional materials such as SMAs have been already also conceived [26,27].

The fundamental characteristics of the SMAs are the capabilities to recover ("remem-

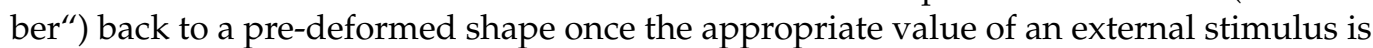
applied [28-30] and to sustain a large reversible deformation usually ranging from 5\% to $10 \%$ [31-34]. The former characteristic of the SMA is referred to as the "shape memory effect", while the latter one is known as the "superelasticity or pseudoelasticity". Although a large number of the SMAs such as the copper-based SMA (e.g., Cu-Zn-Al) [35] or the iron-based SMA (e.g., Fe-Mn-Si) [36] has been found, the NiTi SMAs (Nitinol) are the most studied [37] and preferred in the majority of recent applications [38]. This is mainly due to the fact that the NiTi SMAs have many other excellent properties such as the biocompatibility, high corrosion and wear resistance, high power to weight ratio and the low energy consumption. Moreover, the NiTi SMAs in the form of thin film can be easily prepared by the standard deposition techniques such as the magnetron sputtering or the arc deposition (for detailed discussion see Section 3.1), which have boosted their use in MEMS/NEMS applications in the latest years. Among the NiTi-based MEMS/NEMS applications we may find the microactuators and micropumps, as well as the mass, force, and temperature sensors [39]. We note that problems with fatigue, a large hysteresis and a low actuation speed are among the main remaining challenges in the SMAs-based thin films [40].

The shape memory effect has been also found in a specific class of the stimuliresponsive polymers known as the SMPs [41]. In this case the memory effect utilizes the polymer glass transition (melting/crystallization), as is discussed in detail in Section 2.2, while for SMA the memory effect a result of the diffusionless martensitic transformation (detailed discussion on SMA is given in Section 2.1). Furthermore, in contrast to the shape changing polymers, where shape changes such as bending occur only under the action of an appropriate external stimulus (i.e., the polymer returns to its original shape once the acting stimulus is removed), the deformation in SMPs reminds even when the external stimulus is discontinued. The SMPs return to their original shape only if the required value of a new external stimulus is applied on them [42]. Importantly, SMPs can exhibit not only the dual and triple-shape-memory behaviors that can be viewed to as the one-way and two-way memory effects observed in SMAs, but also the quadruple (i.e., polymer chain can remember three temporary shapes), quintuple (i.e., polymer chain can remember four temporary shapes) or the even higher ones [43]. Despite the fast progress in preparation and characterization of SMPs, many limitations and challenges like the coupling between the heat generation and thermo-response or the structural and polymer network size problems of SMPs for the nanotechnology applications are still not solved [44].

The purpose of this review is to provide an overview of recent understanding of the growing field of the shape memory materials for MEMS/NEMS applications. We would particularly focus on the progress and issues regarding the SMAs and SMPs thin films and heterostructures preparations, characterization and application based on the latest experimental and theoretical findings. This review article is organized as follows: In Section 2 we briefly outline the underlying mechanisms of the shape memory effect, superelasticity, and the other key features associated with the unique properties of the shape memory materials (e.g., variable effective material properties). The preparation, characterization, and modelling of SMAs, especially the NiTi-based ones in the form of 
thin film, and SMPs are given in Sections 3-5. Finally, in Section 6 we present the examples of the SMAs- and SMPs-based micro-/nanodevices and discuss the future challenges and possible research directions using both the experimental and theoretical approaches.

\section{Fundamental Properties of Shape Memory Materials}

\subsection{Shape Memory Alloys}

The shape memory effect and the superelastic behavior are the fundamental properties of SMAs, which have been also exploited in several the commercial applications [45-47]. Both of these properties of SMAs are associated with a diffusionless martensitic transformation [35]. In the case of the NiTi SMAs, the martensitic transformation allows the reversible changes in the crystal structure of NiTi between the body-centered cubic (austenite) structure and the martensite, which can be monoclinic, orthorhombic, rhombohedral, or trigonal [48]. Moreover, the martensite can be also either twinned or detwinned; therefore, it enables together with the austenite phase to achieve up to six different transformation scenarios as also shown in Figure 1 [49]. Upon cooling, the temperature at which the austenite starts transforming to the martensite in stress-free conditions is known as the martensite start temperature $M_{s}$. Correspondingly, the martensite finished temperature $M_{f}$ refers to the temperature at which the austenite to martensite phase transformation is completed. Then, during heating, the martensite starts transforming back to the austenite at the austenite start temperature $A_{s}$ and finishes at the austenite finish temperature $A_{f}$. Notice that these temperature driven transformations exhibit hysteresis, which depends on the NiTi SMA preparation processes and the material composition [32,33].

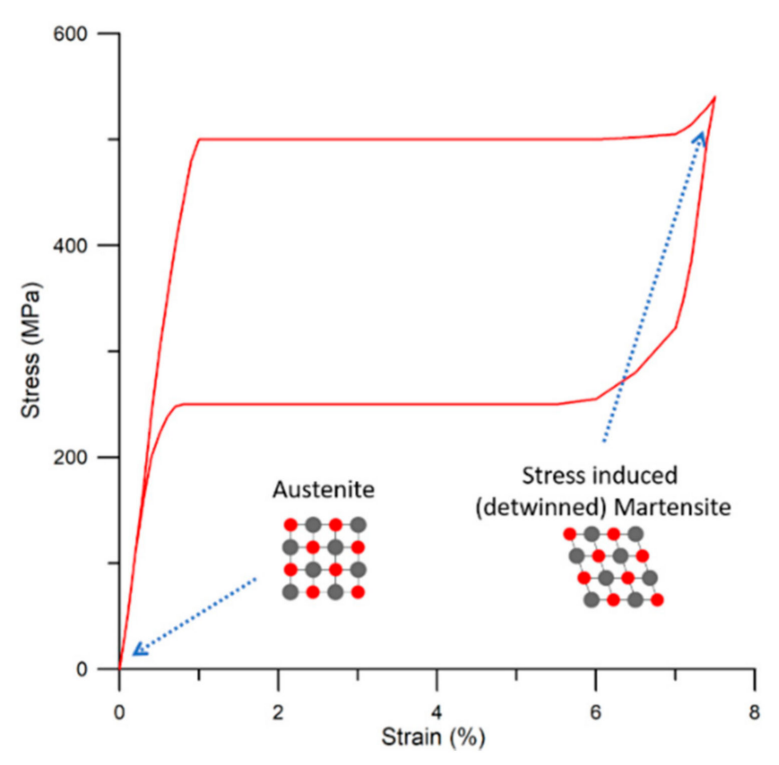

(a)

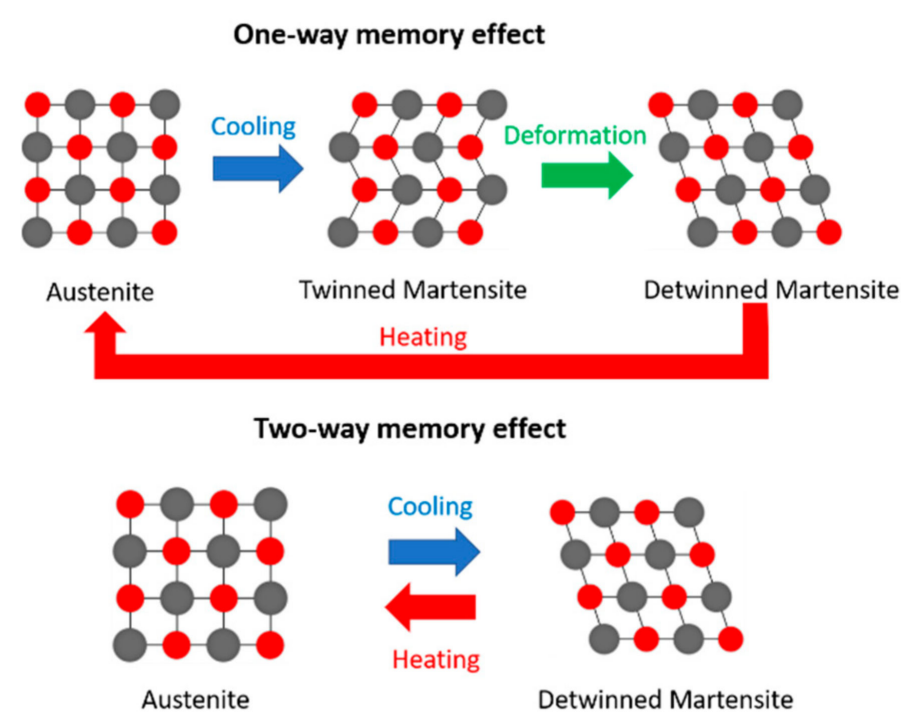

(b)

Figure 1. The fundamental properties of the NiTi SMA with their basic principles: (a) Superelasticity, and (b) One-way and two-way memory effects.

The martensitic transformation in the NiTi SMA can be also induced by external mechanical stresses acting on the austenite [50]. This stress-induced transformation does not require any thermal actuation and can be realized in the temperature range from $A_{f}$ to $M_{d}$, where $M_{d}$ corresponds to the highest temperature at which the stress-induced martensitic transformation can be realized. We emphasize that the stress-induced martensitic transformation allows the NiTi SMA to sustain a large recoverable deformation of several percent (i.e., when the mechanical stress is removed, the NiTi returns to its original "undeformed" shape) [51]. This unique property of the NiTi SMAs is referred to as the superelasticity and is illustrated in Figure 1a. 
The one-way memory effect, which is associated with the temperature-induced martensitic transformation, enables the significantly deformed martensite phase to be recovered by heating to its original shape (i.e., austenite). We have to point out that, in some practical situations, it is desirable that the NiTi SMA can be "trained" to remember its shape at both high (austenite) and low (martensite) temperatures known as the two-way memory effect [52,53]. Interestingly, the two-way memory effect can be also found in other types of SMA such as Fe-Pd ones [54]. Differences between the one- and two-way shape memory effect are depicted in Figure 1b.

In addition to the reversibility of large deformations, the diffusionless martensitic transformation often induce changes in the multiple material properties of SMA. For example, at low temperature, the NiTi SMA is in a relatively soft and deformable martensite phase with the Young's modulus ranging from 25 to $40 \mathrm{GPa}$ [55]. When heated, the martensite phase starts transforming to the austenite phase and, correspondingly, the Young's modulus increases. The Young's modulus of the austenite can reach up to $83 \mathrm{GPa}$ [55]. The Yield strength of the NiTi SMA is both the alloy preparation process and temperature dependent, that is, for a particular alloy composition the Yield strength of the martensite phase is of $117 \mathrm{MPa}$, while for the austenite phase this stress can reach $349 \mathrm{MPa}$ [56]. In general, many other physical properties of the NiTi SMA like the coefficient of thermal expansion, thermal conductivity, electric resistivity, and the magnetic susceptibility are lower (higher) for the martensite (austenite) phase [38,57]. For reader's convenience, the fundamental mechanical and physical properties of the NiTi SMA in both the martensite and austenite phases are summarized in Table 1.

Table 1. The fundamental mechanical and physical properties of NiTi shape memory alloys (SMA) [35,55].

\begin{tabular}{cccc}
\hline Property of NiTi & Units & Martensite & Austenite \\
\hline Density & $\mathrm{g} / \mathrm{cm}^{3}$ & & $\sim 6.45$ \\
Poisson's ratio & - & & $\sim 0.33$ \\
Ultimate tensile strength & $\mathrm{MPa}$ & up to 1900 \\
Young's modulus & $\mathrm{GPa}$ & $25-40$ & $60-83$ \\
Yield strength & $\mathrm{MPa}$ & $70-140$ & $195-690$ \\
Thermal conductivity & $\mathrm{W} /(\mathrm{m} \cdot \mathrm{K})$ & 8.6 & 18 \\
Coefficient of thermal expansion & $\mathrm{K}-1$ & 6.6 & 11 \\
Magnetic susceptibility & $\mathrm{emu} / \mathrm{g}$ & 2.4 & 3.8 \\
Electric resistivity & $\Omega \cdot \mathrm{cm}$ & 76 & 82
\end{tabular}

The performance of the prepared NiTi SMAs can be notably improved by the various strategies such as aging [58] or post-deformation annealing [59]. However, these treatments can often generate the intermediate rhombohedral phase (R-phase), which changes the path of the martensitic transformation from the austenite $\leftrightarrow$ martensite to the austenite $\leftrightarrow$ R-phase $\leftrightarrow$ martensite. Moreover, in contrast to the austenite $\leftrightarrow$ martensite transformation, the R-phase transformation (i.e., austenite $\leftrightarrow$ R-phase) evidences some interesting properties like the narrow thermal (stress) hysteresis and, consequently, the superior sensitivity to the temperature (stress) changes [60], a relatively high stability during the thermomechanical cycling [61] and a high fatigue resistance [62]. Nevertheless, difficulties related to the temperature domain separation of the martensite and R-phase, problems associated with controlling the R-phase transformation temperatures and the small transformation strain [63] are among the main issues that are still restricting the widespread use of the R-phase in the recent nanotechnology applications [64]. 


\subsection{Shape Memory Polymers}

In contrast to SMAs, where the memory effect is an intrinsic property, in SMPs the memory effect is only possible after introducing the netpoints and molecular switches to the polymer structure (i.e., the shape memory effect is not the SMPs intrinsic property) [65]. These netpoints, which can be either the molecular interactions or the chemical bounds, connect different switching domains (i.e., the polymer chain segments) and define the permanent shapes, while the switching domains (segments) are then responsible for the temporary shape fixation [66]. This means that the temporary deformation of the polymer network, which is determined by the chain segments sizes, lengths, and their orientations, are fixed by the netpoints (e.g., reversible chemical bounds). In addition, the memory effect in SMPs yields the controlled release and/or storage of the entropic energy, that is, the polymer macroscopic deformation has to produce the entropic energy changes. The SMPs can be also actuated by the various types of external stimuli like thermal, electrical or acoustic ones, and based on the designed network structure, they can exhibit irreversible or reversible memory effects [67-70].

In the case of the irreversible (one-way) memory effect, the necessary "programming" can be performed by, for instance, deforming the SMP heated to a specific temperature $T_{\text {reset }}$ (i.e., the temperature above the polymer thermal transition), holding it for a certain period of time and, afterwards, cooling it down to the low temperature $T_{\text {low }}$ (i.e., the temperature below either the polymer's glass or the crystallization temperature) and removing the external stress. The original shape can be recovered upon heating the SMP back to the temperature $T_{\text {reset }}$ [71]. The programming-recovery cycle can be, in general, almost infinitely repeated, that is, the number of cycles is only limited by the degradation of the SMP. Furthermore, the polymer network can be also designed to "remember" the multiple temporary shapes (see Figure 2a) [72]. The main drawback of the one-way memory effect is the irreversibility of the shape change, that is, when the original (or the next temporary) shape is recovered then the (previous) temporary shape is "lost" and can be obtained again only by a new programming.

In contrast, the reversible (two-way) memory effect enables the SMP to switch forward and backward between two distinct shapes as depicted in Figure 2b [73]. This reversibility is achieved by the crystallization(melting)-induced directional elongation (contraction) in the anisotropic polymer network (chain) [74]. This behavior can be achieved in the similar manner as for the irreversible SMP, that is, when the SMP is heated to the temperature $T_{\text {reset }}$, then, it is deformed by an external force, and finally, it is cooled to the temperature $T_{\text {low. }}$. At this stage, the external force can be either removed (i.e., for polymers with the stress induced within the network segments) or kept [75]. The new temporary shape can be reached by heating the polymer to the separation temperature $T_{\mathrm{S}}$, that is, the temperature at which two different crystalline phases within the designed polymer network (different chains) can be separated (see Figure 2b). It immediately implies that the original (or new) temporary shape can be obtained from the new (original) shape just by cooling (heating) the polymer to the temperature $T_{\text {low }}\left(T_{\mathrm{s}}\right)$ and this reversible change between these two temporary shapes can be indefinitely repeated (i.e., the number of shape cycles is only limited by the possible degradation of the polymer) [76]. These temporary programmed shapes can be "forgotten" by heating the polymer to the temperature $T_{\text {reset }}$. Similarly, to the irreversible (one-way) memory effect, the new programming is then required to obtain a new set of the temporary shapes [77].

The main advantages of SMPs are their relatively low cost, high recovery shape (deformation ability), low density, changeable mechanical properties, biocompatibility, shape recovery by various external stimuli (e.g., heat, light, electrical, and magnetic) and chemical stability. The fundamental properties of SMPs are, for the convenience of the reader, presented in Table 2. 


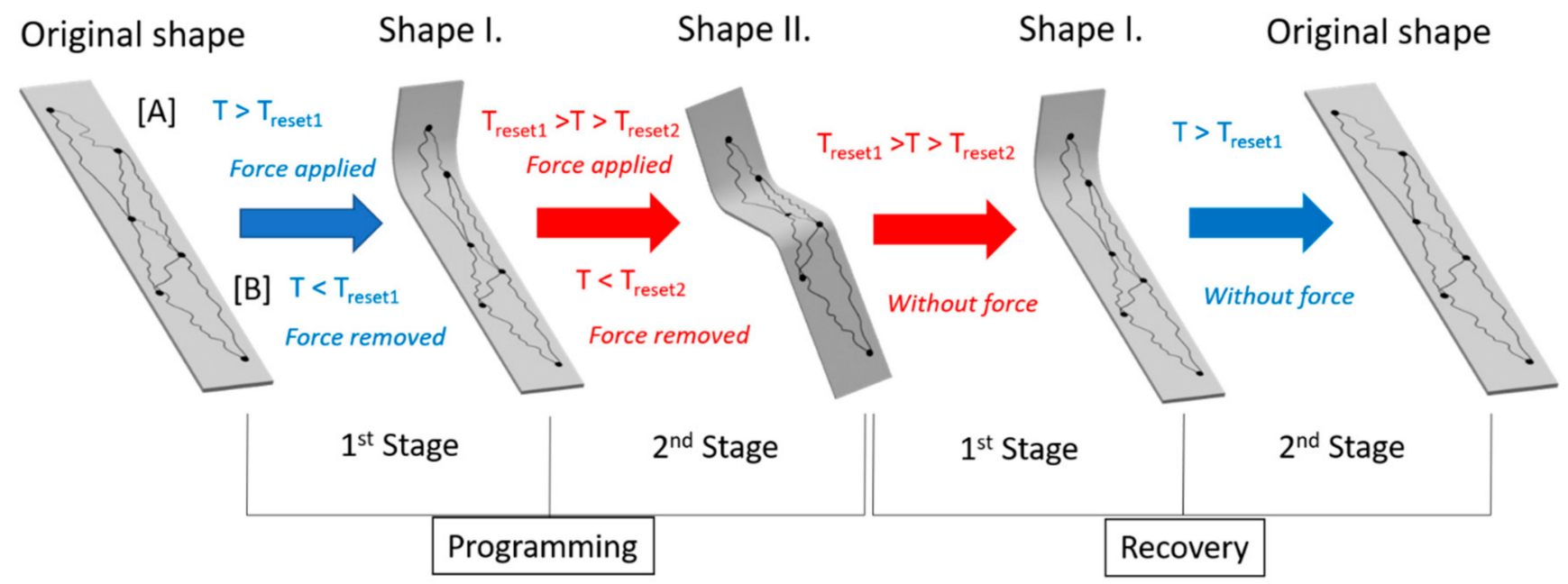

(a)

Original shape

Shape I.

Shape II.

Shape I.

Original shape

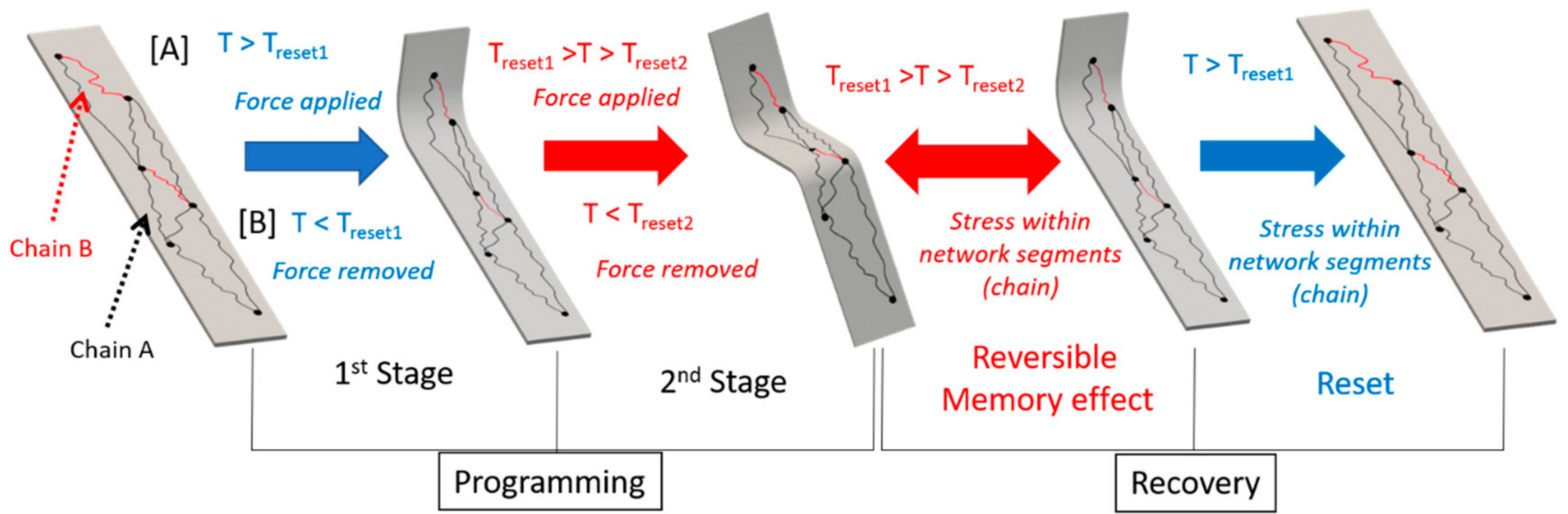

(b)

Figure 2. Programming-recovery cycle of shape memory polymers (SMP): (a) irreversible memory effect, and (b) reversible memory effect. Here $[\mathbf{A}]$ stands for first step and $[\mathbf{B}]$ for the second step of the programming.

Table 2. The fundamental mechanical and physical properties of SMPs [78].

\begin{tabular}{ccc}
\hline Property of SMP & Units & Usual Value(s) \\
\hline Density & $\mathrm{g} / \mathrm{cm}^{3}$ & $0.9-1.1$ \\
Young's modulus of temporary shape $\left(T<T_{\text {reset }}\right)$ & $\mathrm{GPa}$ & $0.01-3$ \\
Young's modulus of original shape $\left(T>T_{\text {reset }}\right)$ & $\mathrm{GPa}$ & $10^{-4}-10^{-2}$ \\
Stress (for deformation / from recovery) & $\mathrm{MPa}$ & $1-3$ \\
Thermal conductivity & $\mathrm{W} /(\mathrm{m} \cdot \mathrm{K})$ & $0.15-0.3$ \\
Recovery speed & $\mathrm{sec}$ & $1-600$ \\
Recovery deformation & $\%$ & $<800$ \\
\hline
\end{tabular}




\section{Preparation of SMAs and SMPs Thin Films and Heterostructures \\ 3.1. Shape Memory Alloys}

The micro-/nanosized SMAs, usually in the form of thin films, have been extensively studied for more than 30 years. One of the earliest studies on the SMAs-based thin films was performed in 1990 by Busch et al. [79]. In their work, the shape memory effect in NiTi SMAs films prepared by DC magnetron sputtering was successfully demonstrated. During the past three decades, the memory effects and/or superelasticity have been also observed in other types of the SMAs thin films including the NiMnGa [80] and Co-Fe(-Mn)Si Heusler alloys [81] or the CuZnAl based ones [82]. Nevertheless, the majority of studies focus only on the NiTi and NiMnGa SMAs thin films and heterostructures intended for design of the various functional MEMS/NEMS. These SMA films and heterostructures can be prepared by physical/chemical vapor deposition techniques (PVD/CVD) such as the arc deposition [83], magnetron sputtering [84], target ion beam deposition [85], or the focus ion beam [86]. The choice of the particular deposition technique depends on the SMAs film purposes.

The NiTi SMAs used for the cardiovascular and biomedical implants are designed to operate in vivo $[87,88]$. Under the in vivo conditions, a lack of biocompatibility may lead to serious health problems such as the restenosis formation in stents or the prosthetic infection. Plenty of these health problems are closely connected with the release of toxic $\mathrm{Ni}$ into the organism via defects in the $\mathrm{TiO}_{x}$ layer formed on the surface of the NiTi SMA film(s) $[89,90]$. The surface treatment, usually in the form of deposited ultrathin film, which is necessary to prevent the release of the toxic $\mathrm{Ni}$, can be performed using the arc deposition technique shown in Figure 3a [91]. This technique can produce low porosity films with the precisely-controlled chemical composition and good corrosion resistance. Moreover, it has been demonstrated that the NiTi SMA thin films prepared by the arc deposition technique have a good chemical homogeneity and composition identical to the target materials [92]. The main disadvantages of the arc deposition technique are (i) the possible generation of the micro-droplets; (ii) the necessity of precisely controlling the physical properties of the plasma and the vacuum arc; and (iii) difficulties with preparation of the multilayered and multicomponent films [93].

Thin films prepared by magnetron sputtering (see Figure $3 b$ ) have the uniform thickness and are free of the micro-droplets [84]. In addition, this technique allows the fabrication of the multicomponent films, particularly binary (e.g., NiTi SMAs films [94]), ternary (e.g., NiMnGa SMAs films [95]), the quaternary (e.g., TiNiHfCu SMAs films [96]). Hence, most of the SMAs thin films and heterostructures are produced by the magnetron sputtering. For the NiTi SMAs films, the sputtering can be performed from either the separate high purity $\mathrm{Ni}$ and Ti targets [97] or only a single NiTi target of a given material composition [98]. Since phase transformation temperatures depend strongly on the composition [38], the precise control of the sputtering parameters is essential for the preparation of the NiTi-based MEMS/NEMS.

The NiTi films sputtered at the high temperatures $\left(\sim 500^{\circ} \mathrm{C}\right)$ are already the phase transforming crystalline ones [98], whereas those prepared at the room (low) temperatures are amorphous and, as such, they require the post-annealing to obtain the shape memory properties and a good tribological behavior [99]. Notice that during preparation of the NiTi film the interlayer stress ranging from a few of $\mathrm{kPa}$ to hundreds of MPa can be often generated [100]. This stress, which can strongly affect the transformation temperatures of $\mathrm{NiTi}$, originates from a combination of the thermal stresses (i.e., the mismatch between the coefficient of thermal expansion of NiTi and the substrate materials like silicon), phase transformation stresses (i.e., stresses caused by the reversible phase transformation in NiTi) and the intrinsic stresses (i.e., stress from the material deposition conditions) [101,102]. Furthermore, as discussed previously, on the surface of sputtered NiTi SMAs film the uniform oxidative layer, independent of the film thickness, is naturally created. As such, for the biomedical applications the required surface treatment of the sputtered NiTi SMAs films can be fulfilled by, for example, the subsequent use of the arc deposition technique [91]. 


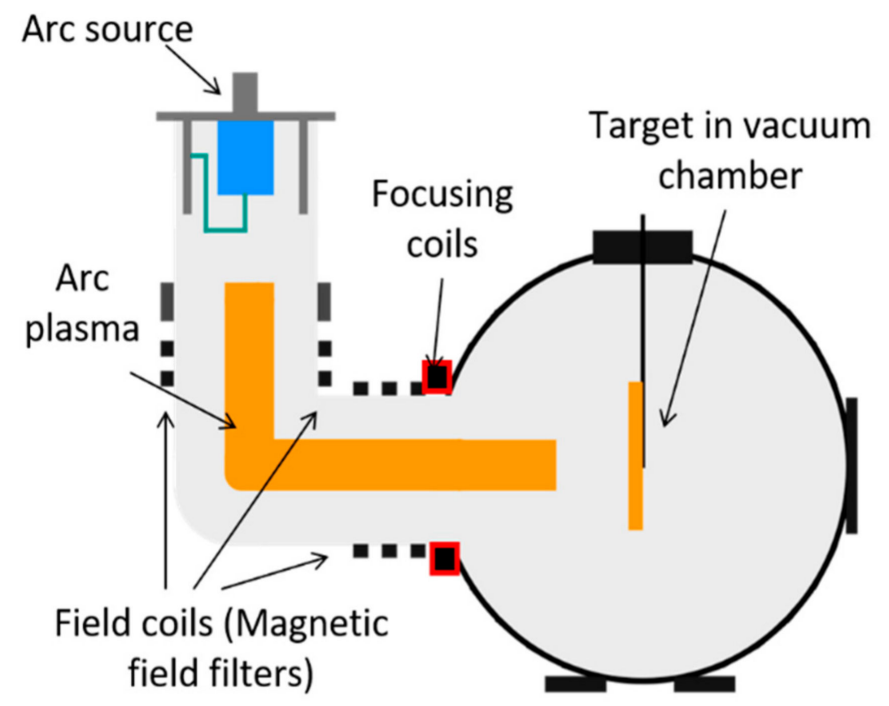

(a)

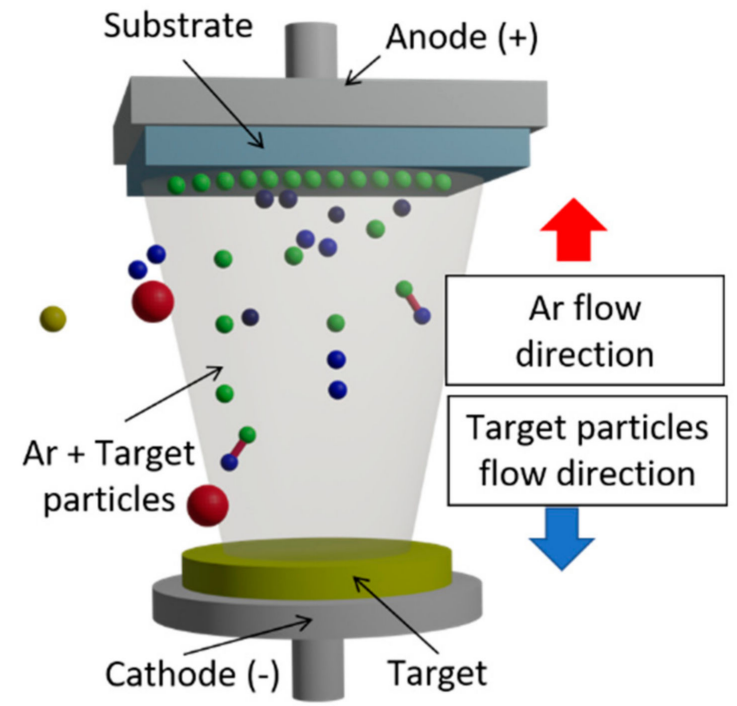

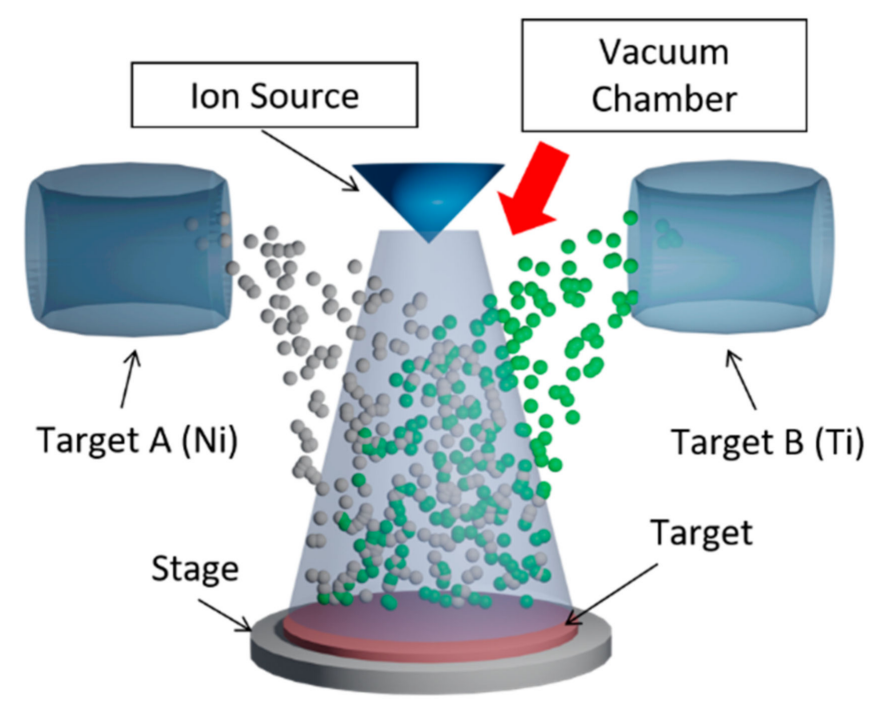

(b)

(c)

Figure 3. Standard deposition techniques used to prepare the majority of SMAs thin films (a) arc deposition, (b) magnetron sputtering, and (c) target ion beam deposition.

It is important to note that with a further decrease of the film thickness to the nanoscale dimensions, the impact of the oxidative surface layer on the overall physical properties of the film becomes more preponderant. For ultrathin films (i.e., below 100 nm) the transformation behavior of NiTi can significantly deviate from the one known for the bulk materials [103]. Hence, to ensure the prepared ultrathin film can reach the desired functional properties its composition during the film preparation process(es) must be precisely controlled. The target ion beam deposition technique (see Figure 3c) that combines the advantages of the sputtering and ion beam deposition, enables the fabrication of the high quality NiTi SMAs ultrathin films of thickness below $100 \mathrm{~nm}$ [85]. In this technique, the desired control of the NiTi SMA film composition uniformity at the nanoscale is achieved by modulating, through the precise controlling of the pulse width and period, each target bias. Interestingly, the fabrication of the NiTi SMAs nanowires by the target ion beam deposition technique followed by the nanoskiving has been recently demonstrated [104]. 
It is worth noting that to prevent the possible interdiffusion between the NiTi SMA film and some types of the nanotechnology used substrate materials such as the silicon requires deposition of a few nm thick $\mathrm{Si}_{3} \mathrm{~N}_{4}$ film on the substrate prior the own sputtering of the NiTi material [49].

\subsection{Shape Memory Polymers}

Shape memory polymers usually in the form of the heterostructures and/or thin films can be fabricated by either standard molding techniques such as the injection, compression, resin transfer and the extrusion [105] or also by the chemical vapor deposition (CVD) [106], and more recently the 3D and 4D printing [107]. Plenty of review papers and books on the SMPs prepared by the standard techniques have been already published (see for instance Reference [108]); therefore, here we provide a brief description of the SMPs prepared just by the CVD and 3D printing technologies.

The degree of cross-liking, which describes the number of bonds linking two polymer chains, as well as the thickness of SMPs can be precisely controlled by using initiated CVD [109]. In this technique (see Figure 4a), the initiator material(s) together with the monomer(s) flows into the vacuum chamber, where they interact with the heated filaments. Then, the initiator is broken into the radical enabling the free-radical polymerization at the high deposition rates. As a result, this technique is highly suitable for deposition of SMPs on the organic substrates [110], fabrication of free-standing films with high aspect ratios [111] or ultrathin films with thickness of tens of nm [112]. We note that the deposition of heating-responsive shape memory polytetrafluoroethylene (PFTE) considered for the next generation of the organic electronics, by initiated CVD technique has been already demonstrated [110].

The main advantage of 3D printing technology is in its capability to fabricate the complex shapes with a precise microstructure architecture. Hence, the combination of 3D printing and SMPs allows designing heterostructure(s) capable of achieving the complex shape change(s) in response to the external stimulus [113]. The majority of the SMPs can be fabricated by 3D printing technologies such as the fused deposition modelling, digital light processing, stereolithography, or polyJet. Among them, the fused deposition modelling is the most commercially successful 3D printing technology because of its simple operation, low cost, and high reliability. This technology that utilizes the extraction of the thermoplastic filaments to create layer-by-layer heterostructures (see Figure $4 \mathrm{~b}$ ), is primarily used to fabricate the majority of thermal responsive SMPs $[20,114]$. In addition, the multiresponsive SMPs based heterostructures consisting of the cross-linked polycyclooctene, which is well-known for its capability to sustain an extraordinarily large deformation of about $700 \%$, with embedded thermal (functional) fillers can be also produced by the fused deposition modelling [115]. They also demonstrated that the electro-response under a low voltage can be easily achieved by adding the multi-walled carbon nanotubes to the 3D printed polycyclooctene based heterostructure.

The digital light processing technique employs a digital light projector for the solidification of a single layer of the liquid resin as also depicted in Figure 4c. The digital light projector flashes the image of the single layer to a built platform submerged in a tank with resin; therefore, this technique is relatively fast (i.e., the entire single layer is created at once) and can be used to fabricate highly detailed structures. Recently, the functionally graded materials with tunable mechanical properties for future application in metamaterials or soft robotics have been prepared by combining the grayscale digital light processing with the two-stage curing ink [116]. Importantly, this procedure allows the preparation of the 3D structures with material properties (e.g., modulus, glass transition temperature or the Poisson's ratio) that may vary within a single material layer. It has been shown that the polymerization rates can be notably promoted by adding the nanosilica particles into the SMPs resin [117]. The fabricated SMPs-nanosilica 3D structures evidence good shape memory properties and the excellent mechanical strength, and capability to reach high strains. 


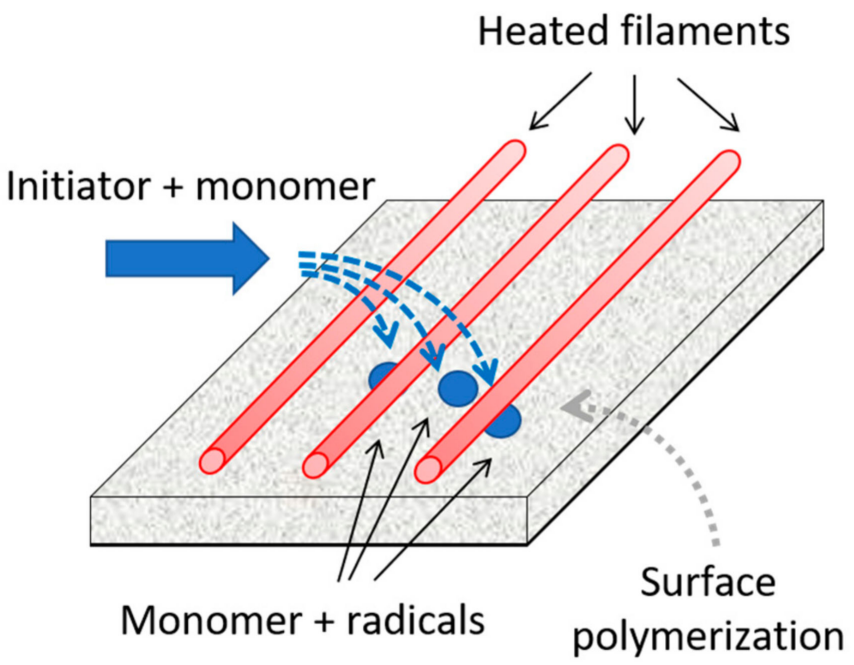

(a)

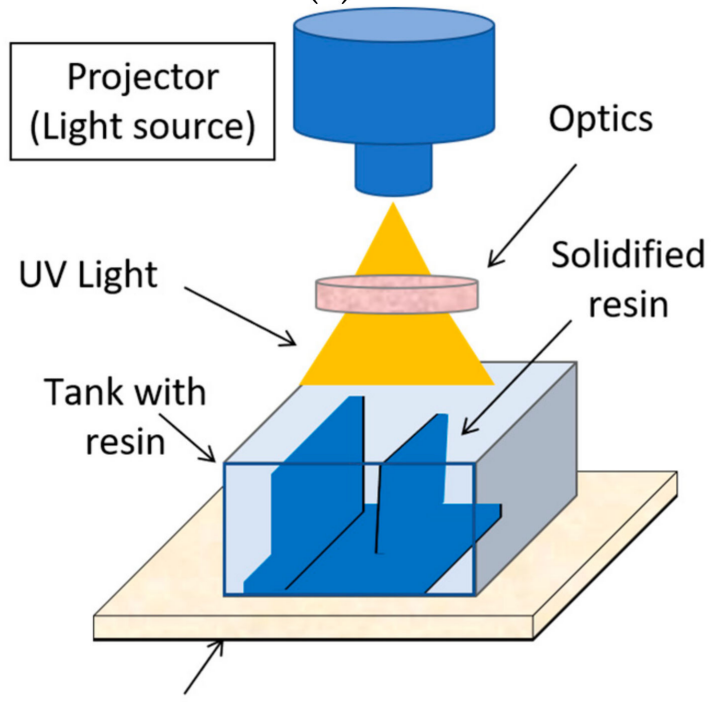

Build Plate

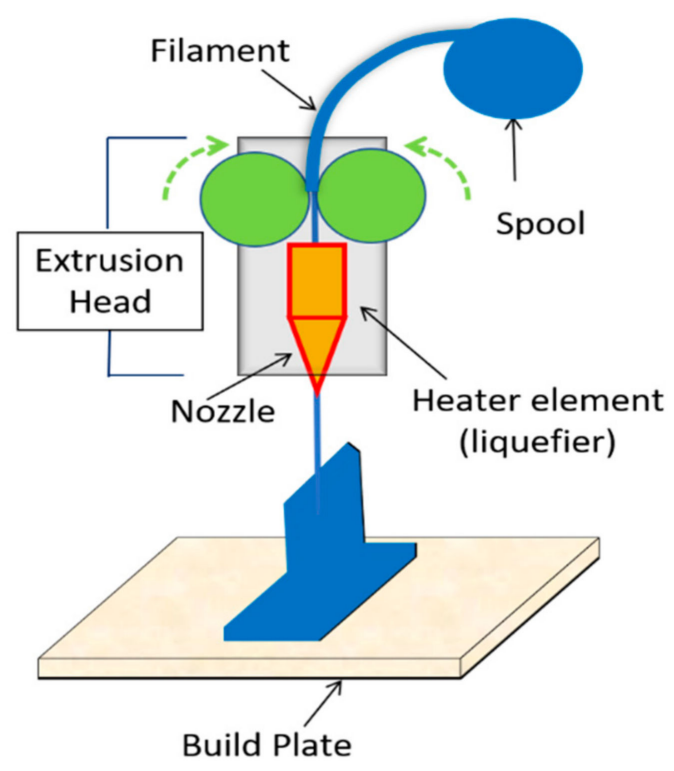

(b)

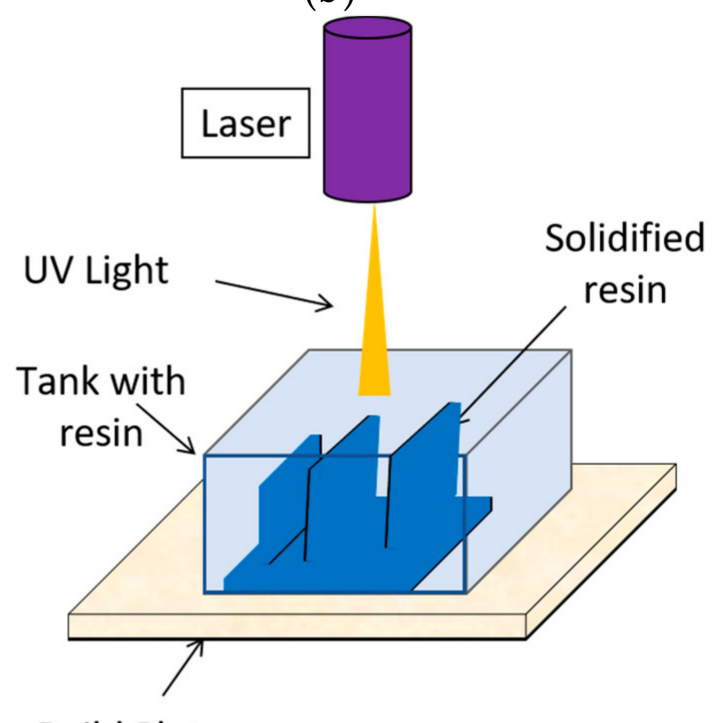

(d)

Build Plate

(c)

Figure 4. Sketch of the (a) initiated CVD, (b) fused deposition modelling, (c) digital light processing, and (d) stereolithography techniques used to prepare the SMPs.

Another liquid resin-based 3D printing technology used to fabricate SMPs is the stereolithography (see Figure 4d). This technology shares many similarities with the digital light processing, namely, it takes an advantage of the ultraviolet light (laser) that draws the contour of the designed shape to the surface of the photopolymer vat to solidify the photopolymer resin. High-resolution SMPs-based heterostructures (up to a few of $\mu \mathrm{m}$ ) can be fabricated by incorporating a high resolution digital micro-display as a dynamic photo mask into the stereolithography [118]. The combination of 3D printing technology with the shape-shifting materials (e.g., termadapt polymers), also known as the 4D printing, have opened possibilities to fabricate the complex shape changeable heterostructures. Multiple 4D printing approaches including the direct ink writing [119] or digital light modulation [107] have been recently proposed and their application potential has been demonstrated. 
There is a current trend in nanotechnology to design the multifunctional smart heterostructures, which are expected to achieve the extraordinary functionalities not feasible by natural materials. These structures can be prepared by combining 3D (4D) printed SMPs with other functional materials such as SMAs or piezoelectric ones. We emphasize that the multifunctional structure consisting of SMPs and piezoelectric materials in the form of nanoparticles has been recently fabricated and its extraordinary functionality demonstrated [120]. This design, which incorporates the nanoparticles made of functional materials into the printed SMPs, may be applicable in flexible electronics, biomedical sensors, or robotics.

\section{Characterization of SMAs and SMPs Thin Films and Heterostructures}

The shape memory effect (shape memory effect and superelasticity), and the changeable mechanical and physical properties in SMPs (SMAs) thin films or heterostructures depends on the prepared polymer network (material composition). As discussed previously in Section 3, the shape memory effect in the NiTi SMAs arises from stress or temperatureinduced martensitic phase transformations of which the characteristic thermomechanical behavior depends strongly on the weight percentage of the contained elements and on the preparation of the alloy. Consequently, the adequate thermomechanical experiments on the micro-/nanosized samples are necessary to ensure that the prepared SMA-based MEMS/NEMS devices can reach the desired functional properties.

The fundamental information needed during the thermomechanical characterization of the SMAs films is their phase transformation temperatures under the stress-free conditions [49]. Knowledge of these temperatures allows determining whether the prepared film (heterostructure) can, in a certain temperature range, potentially behave superelastically or show the shape memory behavior. The phase transformation temperatures in SMAs are characterized by the release/absorption of energy in the form of the latent heat, which can be detected by the Differential Scanning Calorimetry (DSC) technique [121]. Figure 5a shows an example of the DSC curve obtained on the NiTi free-standing film of thickness $1.69 \pm 0.2 \mu \mathrm{m}$ prepared by DC magnetron sputtering technique [122]. Here, the positive heat power peaks observed upon cooling represent the exothermic reactions associated with the transformation of NiTi from the austenite to R-phase and, subsequently, into the martensite phase. Upon heating, the single endothermic heat power peak in Figure 5a corresponds to the transformation from the martensite to the austenite. The starts and ends of these heat power peaks are then correlated to the transformation temperatures of the NiTi SMA.

The phase transformation temperatures of the micro-/nanosized SMAs samples can be also obtained by the four-point electrical resistometry [123]. This method utilizes measurement of DC voltage drop across a sample caused by the electrical resistance. Because the contribution of the sample deformation to the electrical resistance is small, it is possible to associate the evolution of electrical resistance with the changes of electrical resistivity of the material [124]. We remind the reader that the electrical resistivity is an intrinsic material property, which for metals is strongly the atomic organization dependent and, as such, it is affected by the crystal phase transformations. Figure 5b shows the electrical resistance evolution in the $\mathrm{NiTi} / \mathrm{PZT} / \mathrm{TiO}$ heterostructure, where the reversible austenite-to-martensite transformation temperatures of $2.1 \mu \mathrm{m}$ thick NiTi layer are depicted at the inflection points of the curve [123]. 


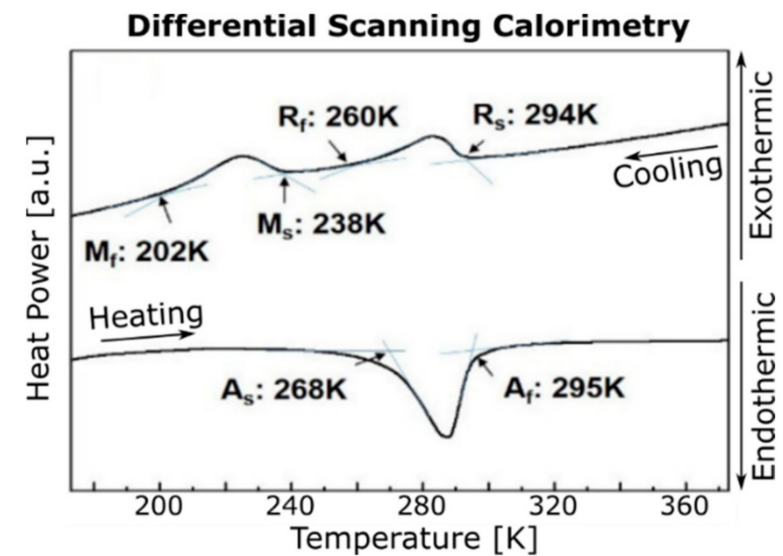

(a)

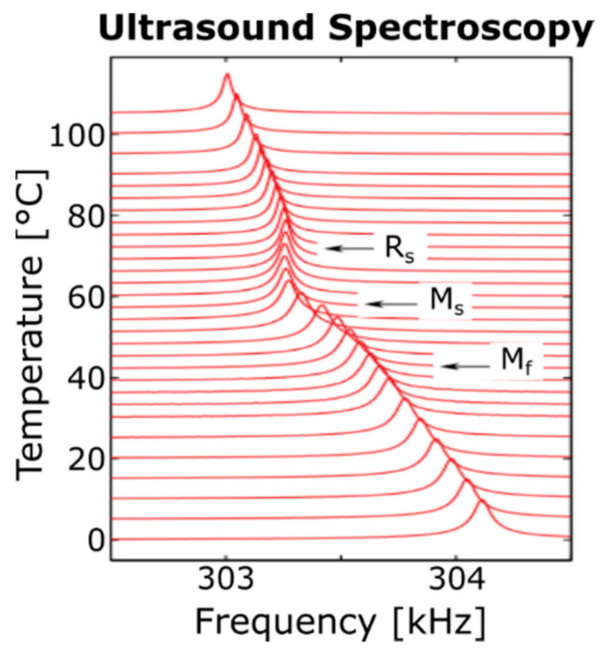

(c)

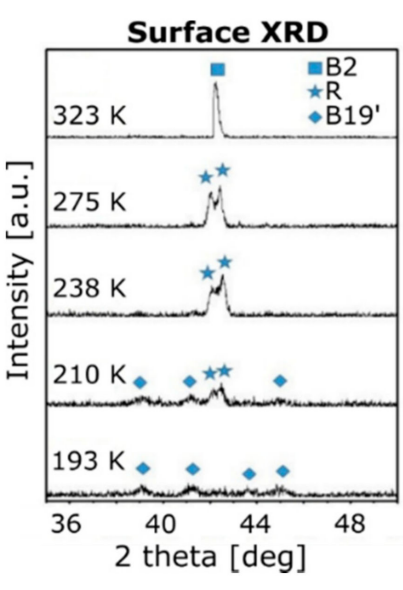

(d)

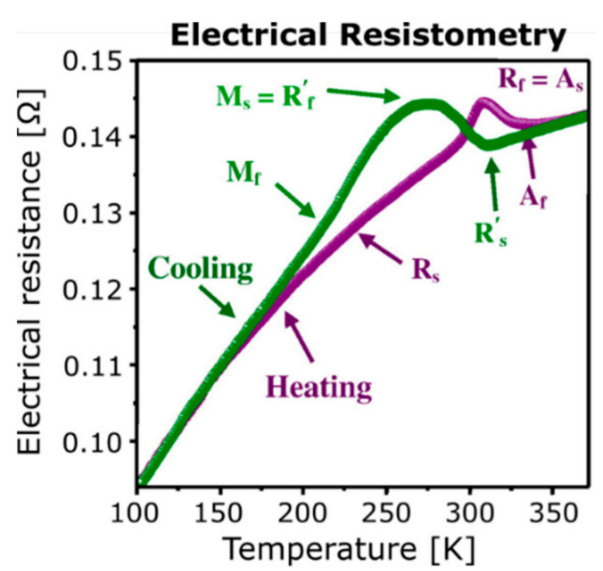

(b)

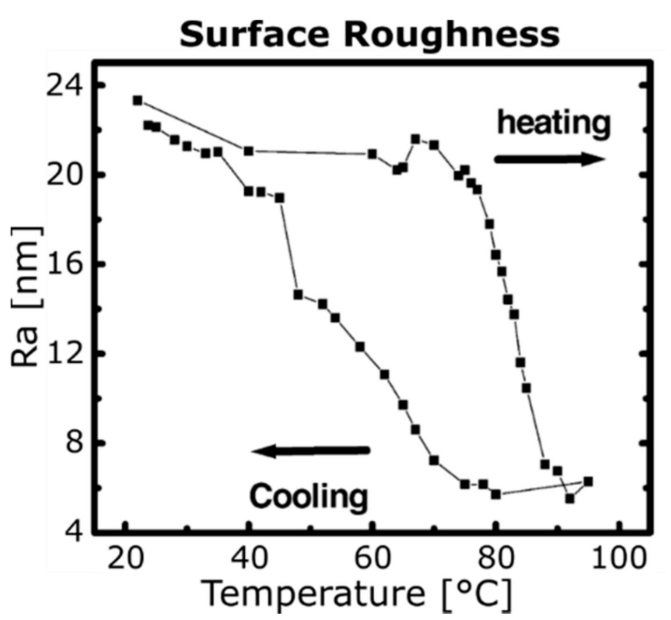

(e)

Figure 5. Results of different methods used to evaluate the phase transformation temperatures in SMA films. (a) Differential Scanning Calorimetry of NiTi film reproduced from [122]; (b) Electrical resistance evolution of NiTi/PZT/TiOx heterostructure reproduced from [123] with permission from Elsevier 2011; (c) Evolution of the resonant spectra of the NiTi film sputtered on Si substrate reproduced from [125] with permission from Elsevier 2015; (d) Surface X-Ray diffraction evolution of NiTi film reproduced from [122]; (e) In-situ surface roughness measurement upon heating/cooling of NiTi film sputtered on Si substrate reproduced from [39] with permission from Elsevier 2004.

Both the DSC and electrical resistometry methods can be applied to the free-standing and constrained thin films. However, for the constrained films (e.g., SMA film sputtered on the elastic substrate), the particular attention must be paid to the possible temperature dependent physical properties of the substrate material(s) and their interactions with the SMA film. For DSC, the substrate must evidence a constant heat capacity within the tested temperature range, ensuring that the heat peaks correspond exclusively to the phase transformation of the SMA film. For electrical resistometry, the substrate and the sample must be electrically isolated to avoid the division of the input current (e.g., for commonly used silicon substrates, the electrical isolation can be realized by adding thin interlayer made of silicon dioxide) [126].

The resonant ultrasound spectrometry (RUS) allows, based on measurement of the normal modes of the prepared sample, the characterization of the elastic constants of SMA thin film sputtered on the elastic substrate [127]. Since the elastic properties of SMA and the transformation temperatures are interrelated with each other, therefore the transformation temperatures can be easily deduced from the observed dependency of the normal modes on temperature $[98,125]$. Figure $5 \mathrm{c}$ presents the normal modes obtained by RUS for $3 \mu \mathrm{m}$ thick NiTi SMA film sputtered on $100 \mathrm{~mm}$ thick silicon substrate [125]. 
The high- and low-temperature surface X-ray diffraction (SXRD) enables the direct identification of the crystallographic phases in the micro-/nanosized SMAs samples at given temperatures [122]. Thus, within the considered temperature range, SXRD can quantify the local volume fractions of the crystallographic phases for each of the considered temperature as shown in Figure $5 d$. It is important to note that this "discrete technique" is usually combined with the continuous technique such as DSC to ensure the correspondence of the physical response of the material with its microstructure evolution. It is worth noting that Figure 5a,c present a DSC response and SXRD for the identical NiTi SMA film [122].

The surface roughness at different temperatures using the Atomic force microscopy (AFM) has been also suggested as an alternative discrete technique for evaluation of the transformation temperatures of constrained SMA films [39]. This technique relies on the fact that the stress-free martensitic phase transformation produces lattice shear and twinning, which creates the local surface deformations as illustrated for the NiTi SMA film sputtered on the silicon substrate in Figure 5e. The surface roughness that shows hysteretic behavior upon a cooling-heating cycle, can be linked to the phase transformations in NiTi. It means that the low-temperature phase (twinned martensite) evidences the higher roughness than the high-temperature phase (cubic austenite).

Determination of the phase transformation temperatures of the nanoscale samples (e.g., the NiTi SMA ultrathin films) is still challenging task that may require usage of the sophisticated devices such as the nanocalorimeters [128]. These devices combine thermal and electrical measurements to track changes in the heat capacity of materials upon heating and cooling. The basic nanocalorimeters are sharing many similarities with the electrical resistometry devices, that is, they use a four-point measurement setup with the tested sample deposited directly on the measurement device. However, for nanocalorimeter, shorter and more intense pulses of the direct current $(I)$ are applied to the sample to heat it at high rates, reaching up to $10^{6} \mathrm{~K} / \mathrm{s}$. The nanocalorimeters achieve the heat capacity measurements with the resolution of at least $1 \mathrm{~nJ} / \mathrm{K}$. Note that the identification of the phase transformation temperatures of the SMA-based ultrathin films such as Ti-Ni-Hf $[129,130]$ and NiTiZr SMAs [131] by nanocalorimeters has been already demonstrated.

It is important to note that the characterization of the shape memory (and superelastic) behavior of the micro-/nanosized SMA and SMP samples is still challenging. It often requires the accurate measurements of forces and displacements in these samples subjected to thermal and/or mechanical loadings. Many testing devices calculate the stresses and/or strains from the experimentally obtained force-displacement data. In bulk materials, the uniaxial tension and compression devices are commonly used for characterizing the shape memory (shape memory and superelasticity) of SMPs (SMAs). In the case of thin films, freestanding samples intended for the uniaxial tensile tests must be carefully peeled off from the substrate to keep their shape straight (i.e., without significant bending). Unfortunately, the internal stress induced during the sample preparation (i.e., sputtering and heat treatment that are discussed in Section 3.1) can cause bending of the free-standing samples. These bent samples can not only alter the test result but also can be easily damaged upon the clamping in the tensile test device. Secondly, the clamping system of standard uniaxial testing equipment is usually not well adapted for the miniature samples.

One of the possible approaches for overcoming difficulties related to the tensile testing of film utilizes an increase of the sample volume by enlarging its width and length, while the sample thickness reminds unchanged. For example, Meng et al. [132] used this approach for evaluation of the superelastic response of $4.0 \mathrm{~mm} \times 15 \mathrm{~mm} \times 5 \mu \mathrm{m}$ Ti-Nb samples. This approach has been also used by Ossmer et al. [133] for testing of the superelastic $20 \mu \mathrm{m}$-thick NiTi samples of $1.75 \mathrm{~mm}$ width and $35 \mathrm{~mm}$ length. In this particular case, the glass plates were bonded to both ends of the investigated sample and, afterwards, this structure was fixed by screws to the tensile machine. This work demonstrated that larger-width samples allow the implementation of in-situ full-field measurements like infrared thermography or digital image correlation. Another approach to perform the clamping of thin films in the uniaxial tensile testing machines was proposed by Namazu 
et al. [134]. Their $4 \mu \mathrm{m}$-thick NiTi samples were designed with hooking holes for clamping them into their in-house-developed tensile machine as also shown in Figure 6a. Noticing that the geometry of their samples was produced directly upon the deposition process. The compression test enables obtaining the key information for understanding the deformation mechanisms in SMA and SMP materials. San Juan et al. [103] proposed a procedure for carrying out micro-compression tests of pillars fabricated using Focused Ion Beam (FIB) (see Figure $6 \mathrm{~b}$ ). They tested superelastic $\mathrm{Cu}$-Al-Ni micropillars using a nanoindentation device and a sphere-conical diamond indenter tip of $0.6 \mu \mathrm{m}$ radius.

\section{Tensile test in films}

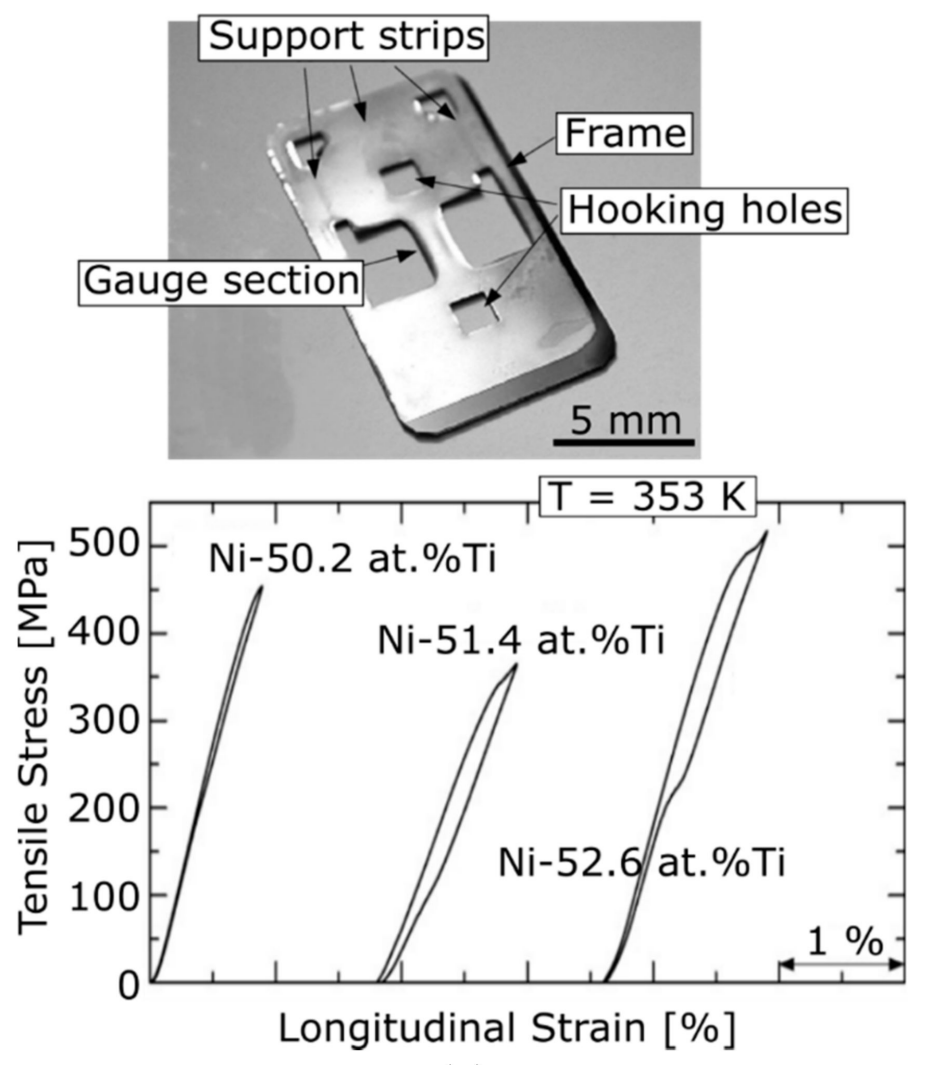

(a)

\section{Compression test in micropillars}
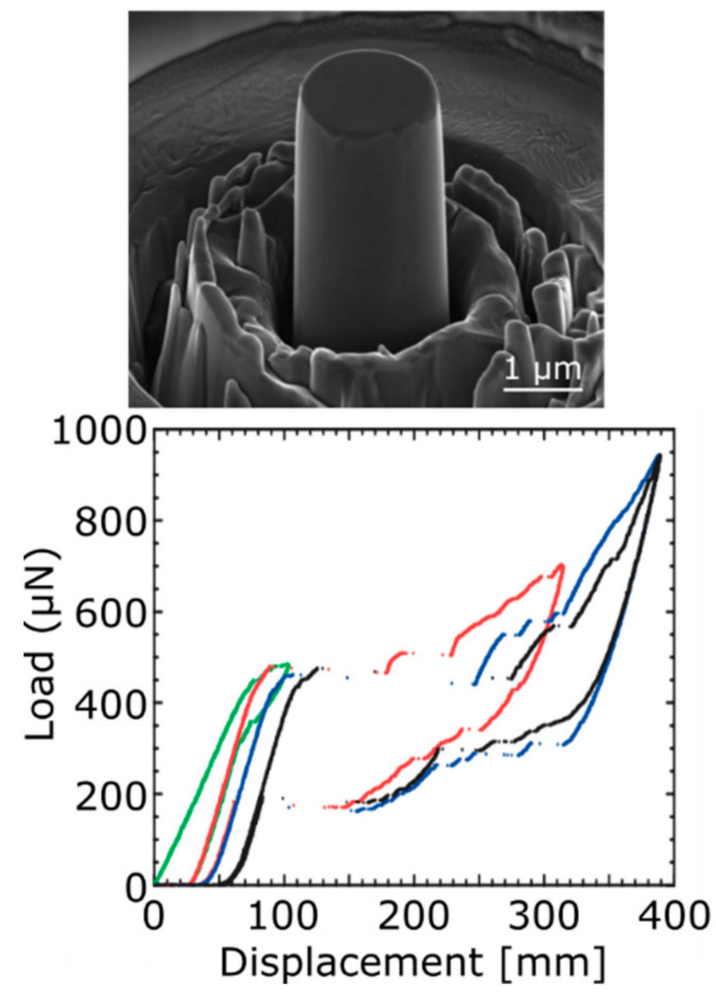

(b)

Figure 6. Uniaxial testing of miniaturized SMA samples: (a) Tensile test of a $4 \mu \mathrm{m}$-thick NiTi film-shaped sample geometry facilitating the clamping on a tensile machine reproduced from [134] with permission from Elsevier 2007. (b) Compression tests of $\mathrm{Cu}-\mathrm{Al}-\mathrm{Ni}$ micropillars using nanoindentation reproduced from [103] with permission from Wiley 2008.

For the design of many microactuators the characterization of the two-way (reversible) shape memory effect is essential. In this case, the evolution of stain is obtained by samples that are subjected to heating-cooling cycles under isobaric conditions. The dynamic mechanical analysis (DMA) has been proven to be suited for this kind of measurement [135]. In this study, the DMA was successfully used to study the $18 \mu \mathrm{m}$-thick NiTi ribbons prepared by melt-spinning. Due to the difficulties associated with sample preparation during the uniaxial testing, the bending tests are preferable for characterization of the functional properties of micro-/nanosized samples. For instance, the Wafer bow testing, which allows the evaluation of the shape memory effect in prepared SMA thin films. This evaluation utilizes measurement of the curvature deformation (bow) in film-substrate assemblies upon heating and cooling and then calculate the in-plane stresses in the film using Stoney's equation [136]. The application of the classical Stoney's equation requires the film to be deposited on the relatively thick substrate and the film must deform under plane stress conditions. The wafer bow testing was applied to characterize: (i) the recoverable stresses 
in NiTi thin films through laser actuation [137] (see Figure 7a); (ii) the actuation stresses associated with the transformation of austenite into r-phase in NiTi submicron films [138], and finally (iii) the effect of thickness and substrate on the stress recoverability in NiTi thin films [102].

Cantilever beam deflection tests, where the modified Stoney's equation is used, are an alternative method for characterization of the shape memory effect in SMA/SMP films [139]. The cantilever beam deflection is usually evaluated by digital image processing during heating or cooling. For instance, Fu et al. [140] used a hot plate in an environment-controlled chamber to change the temperature of a $15 \mu \mathrm{m}$ - thick Si cantilever beam with $5 \mu \mathrm{m} \mathrm{NiTi}$ film. In this case, the deflection was evaluated using images recording by a CCD camera. Similarly, Lambrecht et al. [141] evaluated the deflection of the NiMnGa/Si cantilever beams heated by Joule heating using images recorded by SEM, which allowed them to determine the deflection vs input power of the beams (see Figure $7 \mathrm{~b}$ ). It is noteworthy that in these two examples, it was not possible to calculate the work capacity of the samples since the deflection was induced under unconstrained conditions. Nanoindentation is another experimental technique that is widely employed to assess the mechanical properties of SMP and SMA. Specifically, it allows determining the hardness and elastic modulus of materials [142]. In order for the load vs. depth curves to be converted into the equivalent stress-strain curves, the specific selection of the indentation rate, indenter geometry, and indentation load level is necessary [143].

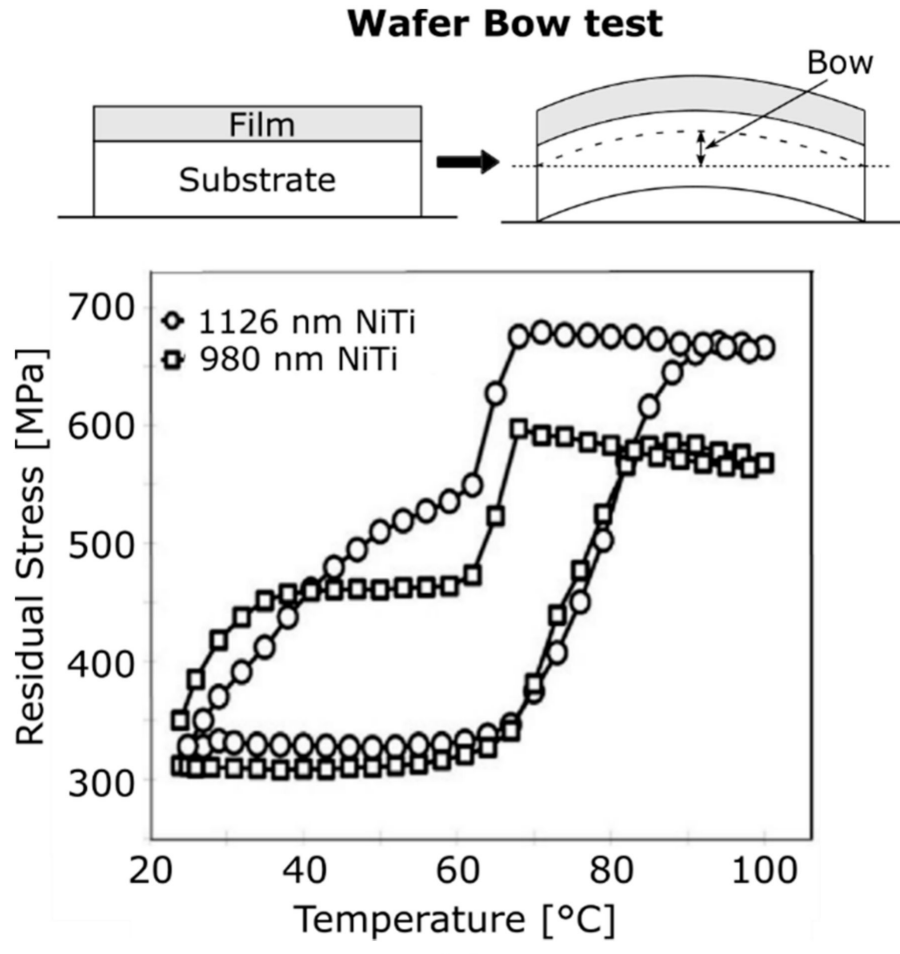

(a)

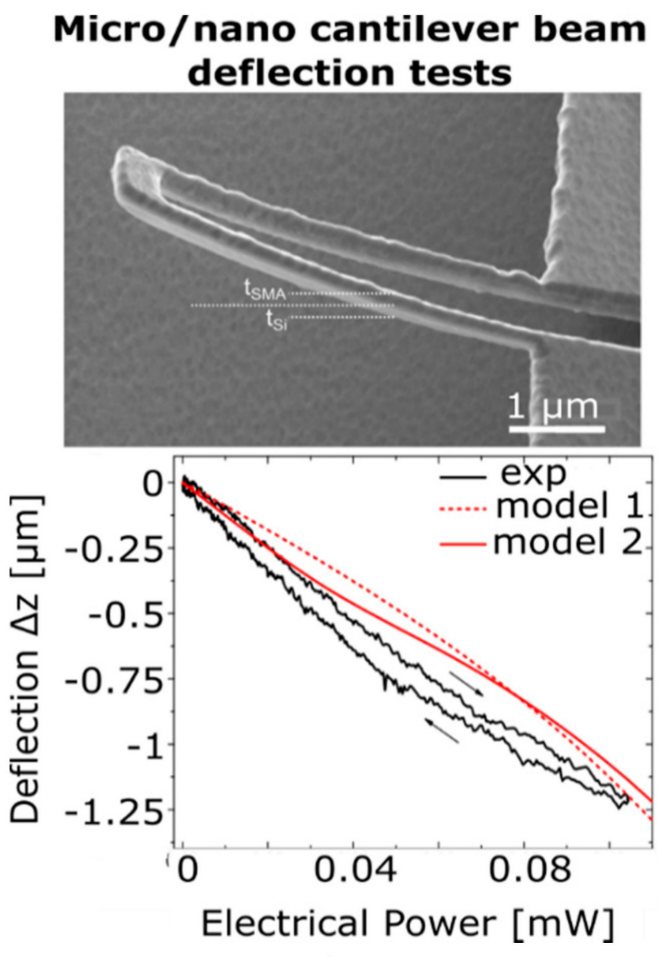

(b)

Figure 7. Bending tests of miniaturized SMA samples: (a) Wafer bow tests reproduced from [137] with permission from Elsevier 2019; (b) Nano cantilever beam deflection test reproduced from [141] with permission from Springer 2016.

The recent development of the nanotechnology and nano-mechanical analysis enabled the development of the strategies combining multiple methods that can be potentially used to characterize the material properties and the phase transformations in the SMP and/or SMA thin films including the phase transformation temperatures [144]. Among them the resonant methods combined with nanoindentation hold promises for non-destructive characterization of even the ultrathin films made of SMAs and SMPs with thickness of tens of $\mathrm{nm}$ [145-154]. It is just the extraordinary force sensing capacity and the high 
spatial resolution that make AFM suitable for characterization of the material properties and shape memory (and/or superelastic) behavior of the micro-/nanosized SMAs and SMPs [150-152]. The manipulation of the single fiber can be realized through the force induced on the tip of AFM. Combination of the AFM with heated stage enables to perform the cyclic thermomechanical test on the micro-/nanosized samples [153]. We note that some of these methods have been proposed for measurement of the biological samples $[155,156]$.

\section{Modelling of SMAs and SMPs Thin Films and Heterostructures}

The understanding of the SMAs and SMPs films and heterostructures in response to a given stimulus is of a great importance in guiding the research and development towards the design of the functional MEMS/NEMS devices. During past decades, many different computational approaches capable to predict the thermomechanical behavior of the SMAs and SMPs components have been developed. These approaches can be classified in terms of the length scale used to describe the deformation phenomena in the material, that is, the macroscopic, mesoscopic, and the atomic ones [157]. The macroscopic or phenomenological approaches are relatively easy to be implemented and do not require high computation power, therefore they are considered in the majority of studies. A drawback of these models is that they do not describe the deformation within the individual grains (crystals), as such, some features of the deformation of the material cannot be reproduced. The mesoscopic (grain) and microscopic (atomic) scale models enable a detailed description of the deformation processes in the investigated material. However, these models (grain and atomic) require essentially a notably higher computation power than the macroscopic ones.

The macroscopic approaches are based on the calculation of the average thermomechanical variables in an elementary volume, in which the properties of the studied material are assumed to be homogeneous. In this case, a set of the internal variables must be chosen to describe the evolving physical phenomena upon thermal and/or mechanical loadings. The number and type of the internal variables vary according to the level of the required complexity, which depends basically on the type of thermomechanical loading and the characteristics of the material-related to the alloying and/or polymer composition and thermomechanical heat-treatment.

The simplest phenomenological models for SMAs assume the volume fraction of martensite and a tensorial deformation variable as internal variables [158,159]. These models allow reproducing the superelastic and shape memory behaviors of SMAs under proportional loadings. Extended variants of these models have been developed to distinguish between the twinned martensite and detwinned martensite [160], to include the viscoplastic and plastic deformations [161-164], and to reproduce the intermediate $R$-phase transformation occurring in a large number of the commercial NiTi alloys [165].

A large number of the constitutive models [166-170] has been developed to predict the shape memory behavior and/or thermomechanical properties in SMPs during the past two decades. For example, by incorporating the friction elements into the standard viscoelastic model the thermomechanical properties of polyurethane can be determined [166]. It has been demonstrated that the recovery time of the SMPs can be accurately predicted by Kevin-Voigt model combined with the Transient Stress Dip Test [171]. In their work the recovery half time, which can be viewed as the relaxation time, predicts more than $90 \%$ of the shape recovery in SMPs. The qualitative description of the shape memory behavior at the microsized samples under the multi-axial loadings by a 3D constitutive model has been proposed by Baghani et al. [172]. Time and temperature dependencies of the shape recovery can be also evaluated by using a generalized Maxwell model and time-temperature superposition principle in FEM simulations [173]. Note that the semianalytical model describing the mechanical response in the thermo-viscoelastic SMPs has been also developed [174]. 
The fast progress in characterization methods allows obtaining the full-field information such as strain [175], temperature [176], and the crystallographic changes [31] in material samples subjected to the uniaxial and multiaxial loading. As a result, researchers have developed advance computation models capable to accurately predict and/or describe the observed changes in the material samples not only in terms of the global forcedisplacement-temperature responses but also in terms of the distribution of the internal variables in material structures. For instance, the simulation of the temperature field in heat exchange scenarios can be performed by implementing the thermomechanical coupling, which characterizes the martensitic transformations in SMAs, into the macroscopic models $[31,177,178]$. Other models have addressed the particular aspects in SMAs such as the localization in NiTi alloys [179-183], the description of their tension-compression asymmetry [184,185], the martensitic transformation anisotropy $[186,187]$ or even the particular coupling between the martensitic transformation and plasticity $[188,189]$. It is important to note that the choice of a suitable phenomenological model depends on the operating conditions of the designed MEMS/NEMS, that is, (i) the SMA elements subjected to the non-proportional and multiaxial loadings may require models including the martensitic transformations anisotropy and tension-compression asymmetry; (ii) elements subjected to cyclic loadings may require models capable of reproducing the evolution of plastic deformation; while elements subjected to high strain rates or changing temperature conditions may need models including thermomechanical couplings. Phenomenological models have been successfully used in design of various SMA/SMP-based MEMS devices such as the micropumps [190], micro-dampers [191], high-speed micro-actuators [192] or the micro-manipulators [193].

Mesoscopic models allow describing the deformation phenomena in the material sample at the grain scale [194]. The integration of the grain behavior into the finite element simulations, which is needed to reproduce the global response of the SMA structures, can be realized by introducing the additional homogenization schemes (e.g., the Mori-Tanaka [195] method). Recently, using this approach, the effects of the grain size on the macroscopic response of the SMA elements have been studied in detail [194-196]. Tessellation method has been also proposed to simulate the "real" polycrystalline structures [197]. The polymer crystallization and the morphology of the phase segregation can be also studied by the mesoscopic models [198,199]. These models usually utilize the mapping of the atomic configuration onto the course one to achieve longer length scales. For example, the mesoscopic models are capable to simulate the transition behavior in SMPs [200]. Thermomechanical behavior and shape memory effect in polyurethane with due account for the hard-segment content has been realized by the multi-scale course grained simulations [201]. In these simulations, the hard and soft segments are represented though different beads, which also take into account the physical crosslinks and the anisotropy in the SMP.

The experimental investigations of the shape memory effect and superelasticity in SMA/SMP at the nanoscale are still highly challenging. For example, it is difficult to observe the grain evolution/changes within individual grains during the phase transformation. The atomic simulations offer an alternative way for studying the processes in SMA and SMP at the nanoscale. It is important to note that the appropriate potentials that are necessary to describe the investigated system have been already developed. Among them the embedded-atom method potential [202] and the modified embedded-atom potentials [203] are mainly used for SMAs. In case of SMPs, the fully atomistic simulations are primarily considered to account for the time-dependent nature of the glass transition, which is required to achieve the memory effect [204]. The atomic simulations have been successfully employed to investigate the twinning and detwinning mechanisms in the nanocrystalline SMA undergo the shock wave [205,206], the effect of cyclic loading on deformation and pseudo-plastic behavior of the nanopillars made of NiTi SMA [207,208], dependency of the deformation in SMA on the grain size and grain boundaries [209,210], the mechanism of the transformation ratchetting in the nanocrystalline NiTi SMA [211], the effect of porosity on the shape memory effect and superelasticity of NiTi [212], the energy 
storage properties of SMP [213], or the glass transition temperature and memory effect in amorphous SMP [214].

\section{Existing Nanotechnology Applications of SMAs and SMPs, and Future Outlook}

Over the years, the application of SMAs usually in the form of thin films has been successfully demonstrated in a large number of MEMS devices such as micropumps [215], microactuators [216], or physical sensors [217]. In the case of micropumps, the fluid pumping (actuation) is realized through the periodically oscillating diaphragm acting upon the chamber with fluid. As such, the micropump performance depends strongly on the achievable deflection of the diaphragm, that is, the higher deflection leads to the larger flow rate. Diaphragms that utilize the shape memory effect in the NiTi SMA have a high force to volume ratio, large strain recovery, and are biocompatible [218]. It is noteworthy that the actuation of NiTi SMA micropumps still requires an external energy input via the electrical wires complicating their integration into lap-on-chip devices. It has been demonstrated that the thermally driven micropumps based on the reversible memory effect in SMPs can be actuated without an external energy input making them suitable for the microfluidic application including the lab-on-chip [219].

Both the one-way and two-way memory effects are applied in the design of the SMA microactuators. The former effect enables the microactuator, which is deformed at the low temperature (i.e., martensite phase) by an external force, to return to its original shape (i.e., austenite phase) upon heating. This actuation principle main advantages are the capability to achieve an extraordinarily large displacement and output force (e.g., for microactuator that consists of the freestanding SMA film connected with a series of the springs made of silicon, the actuation strain of $4.5 \%$ and stress of 200 MPa have been demonstrated [220]). AbuZaiter et al. [221] have shown that the application of an external force can be easily avoided by depositing the NiTi SMA film on the prestressed substrate. In their design, the interplay between the prestressed substrate and changes in the NiTi SMA film material properties (and stress) during the cooling yields the desired deformation of the microactuator. The two-way actuation is an alternative approach, which also does not require the application of an external force. It is noteworthy that the amorphous-crystalline composite TiNiCu SMA exhibits two-way memory effect even without the necessary thermomechanical training making this type of SMA microactuator suitable for MEMS/NEMS and micro-robotics [222]. The two-way memory effect in the NiTi SMA films and microstructures can be also induced by the laser-shock imprinting technology [223]. The drawback of thermally-induced SMA-based microactuators is a relatively low achievable actuation speed ranging from tens of $\mathrm{Hz}$ [224] to a few of $\mathrm{kHz}$ [216] restricting their application in the high frequency devices such as the RF filters or the resonant sensors. Recently, the highfrequency nanomechanical resonators $(\mathrm{kHz}$ to $\mathrm{MHz}$ ) that combine the SMA in the form of thin film sputtered on the "active" elastic substrate, has been proposed [96,225]. In these resonators, the high resonant frequencies (hundreds of $\mathrm{kHz}$ to $\mathrm{MHz}$ ) are obtained by the elastic substrate (e.g., substrate consisting of the piezo-material layers), whereas the phase transforming NiTi SMA enables the up-/downward frequency tuning. These hybrid high frequency resonators can be directly used for the nanoscale material characterization [55] or as the nanomechanical resonator-based mass spectrometers $[55,139]$.

During the past decade, significant progress in magnetic SMAs has enabled the design of a new class of microactuators [226]. The magnetic field actuation enables the designed magnetic SMAs-based microactuators to achieve the high actuation speeds and, as such, to overcome a low actuation speed of thermally actuated SMA resonators [227]. A drawback of the magnetic SMAs-based microactuators is in the difficulties with precise control of their position originating from a large effect of the hysteresis nonlinearity. Recently, the fuzzy neural network models have been developed and considered to predict and optimize the performance of the magnetic SMAs-based actuators [228,229]. These fuzzy logic models may open a doorway for application of magnetic SMAs in various nanotechnology applications. 
It is the biocompatibility, low cost, large deformation, light weight, the capability to adjust the shape memory effect(s) and the changeable materials properties according to the considered device purpose(s) that have made the SMPs highly attractive for the biomedical applications [230]. A versatile method to fabricate the programable liquid-crystalline microactuator has been recently proposed by Liu et al. [231]. They have demonstrated that the necessary changes in the shape and material properties of the designed microactuator can be easily achieved by changing the temperature of the surrounding medium. As such, this kind of actuation has a large application potential in the microfluidic devices, where the external energy input through the wires can be only hardly realized. The wireless SMP microactuator driven by the external radio frequency magnetic field for drug delivery devices has been also reported [232]. This microactuator consists of the thermally actuated SMP material layer and the passive inductor-capacitor resonant circuit. When the external magnetic field is applied, the resonant circuit is heated and subsequently, the bond SMP material layer is deformed. Hence, the radio frequency driven SMP microactuators are of great importance in the design of the drug delivery systems, where the release of a given amount of drug into the blood stream in a specific time is often required. The wireless SMP microactuators can be also used as the building elements in the soft-robotics [233,234]. In many robotic applications, it can be desirable that when needed the actuator movement can be paused in a given pre-defined shape. By combining the crosslinked blends of two-crystalline polymers the expected non-continuous movement can be obtained even without adding an external trigger [235].

There is a current trend in the nanotechnology, materials science, and chemistry to design the multifunctional complex structures that can exhibit properties not feasible by the standard materials. It is expected that these novel structures could perform the multiple-functions (more than one) simultaneously [236]. We envisage that these complex structures would consist of the multiple SMA and/or SMP functional material layers that could be probably prepared by combining the 3D (4D) printing technology with other deposition techniques such as PVD/CVD. As a result, the successful application of these multifunctional materials would require their material-interface-function relationships to be known. The appropriate theoretical models, probably based on the multi-scale modelling, might help to gain the understanding the physics behind these structures. It is generally expected that these smart structures could find an application in the wearable and flexible electronics, energy materials, medical materials, and robotics. For example, the self-healing materials capable of regenerating themselves by applying an appropriate external stimulus or trigger can be used in the artificial arteries or biomedical implants.

\section{Conclusions Remarks}

In this review, we have presented the recent progress in the field of SMAs and SMPs for nanotechnology applications including a brief background of their underlying mechanisms. The main feature of these materials is in their capability to remember the pre-deformed shape. There are many different techniques to prepare micro-nanosized SMAs and SMPs samples usually in the form of thin film. The key technologies used to prepare the micro/ nanosized samples have been discussed in detail in Section 3 of this review. The recent achievement in characterization and modelling of the micro-/nanosized SMAs and SMPs samples have been also presented and the prospective future directions have been proposed. In addition, the promising future of the 3D printing technology and preparation of SMP for nanotechnology applications have been also included in this review. Finally, the successful application of SMAs- and SMPs-based MEMS/NEMS devices such as micropumps and microactuators have been provided. We emphasize here that the field of SMAs/SMPs for nanotechnology application is still growing exponentially and the earliest results shows enormous potential of these shape memory materials in nanotechnology. Overall, present results are of great importance in a future research in the area of the multifunctional smart structures, where combination of multiple SMA and/or SMP elements are considered. 
Author Contributions: I.S.-conceptualization; I.S., E.A. and M.L.-writing original draft; I.S.-the finalization of the manuscript and editing. All authors have read and agreed to the published version of the manuscript.

Funding: This work was supported by the Operational Programme Research, Development and Education financed by European Structural and Investment Funds and the Czech Ministry of Education, Youth and Sports (Project No. SOLID21-CZ.02.1.01/0.0/0.0/16_019/0000760), the Czech Science foundation under the project no. 21-12994J and the Technology agency of Czech Rep. under projects no. TM01000016 and FW01010281.

Data Availability Statement: Not applicable.

Conflicts of Interest: The authors declare no conflict of interest.

\section{References}

1. Stachiv, I. On the Nanoparticle or Macromolecule Mass Detection in Fluid Utilizing Vibrating Micro-/Nanoresonators Including Carbon Nanotubes. Sens. Lett. 2013, 11, 613-616. [CrossRef]

2. Stachiv, I.; Fang, T.-H.; Jeng, Y.-R. Mass Detection in Viscous Fluid Utilizing Vibrating Micro- and Nanomechanical Mass Sensors under Applied Axial Tensile Force. Sensors 2015, 15, 19351-19368. [CrossRef]

3. Fedorchenko, A.I.; Stachiv, I.; Wang, W.-C. Method of the viscosity measurement by means of the vibrating micro-/nanomechanical resonators. Flow Meas. Instrum. 2013, 32, 84-89. [CrossRef]

4. Zhang, X.C.; Myers, E.B.; Sader, J.E.; Roukes, M.L. Nanomechanical Torsional Resonators for Frequency-Shift Infrared Thermal Sensing. Nano Lett. 2013, 13, 1528-1534. [CrossRef] [PubMed]

5. Stachiv, I.; Kuo, C.-Y.; Fang, T.-H.; Mortet, V. Simultaneous determination of the residual stress, elastic modulus, density and thickness of ultrathin film utilizing vibrating doubly clamped micro-/nanobeams. AIP Adv. 2016, 6, 045005. [CrossRef]

6. Stachiv, I.; Vokoun, D.; Jeng, Y.-R. Measurement of Young's modulus and volumetric mass density/thickness of ultrathin films utilizing resonant based mass sensors. Appl. Phys. Lett. 2014, 104, 083102. [CrossRef]

7. Lee, J.; Wang, Z.; He, K.; Yang, R.; Shan, J.; Feng, P.X.-L. Electrically tunable single- and few-layer MoS2nanoelectromechanical systems with broad dynamic range. Sci. Adv. 2018, 4, eaao6653. [CrossRef]

8. Cerdán-Pasarán, A.; López-Luke, T.; Esparza, D.; Zarazúa, I.; De La Rosa, E.; Fuentes-Ramírez, R.; Alatorre-Ordaz, A.; SánchezSolís, A.; Torres-Castro, A.; Zhang, J.Z. Photovoltaic properties of multilayered quantum dot/quantum rod-sensitized TiO2 solar cells fabricated by SILAR and electrophoresis. Phys. Chem. Chem. Phys. 2015, 17, 18590-18599. [CrossRef] [PubMed]

9. Liu, H.; Zhong, J.; Lee, C.; Lee, S.-W.; Lin, L. A comprehensive review on piezoelectric energy harvesting technology: Materials, mechanisms, and applications. Appl. Phys. Rev. 2018, 5, 041306. [CrossRef]

10. Matheny, M.H.; Emenheiser, J.; Fon, W.; Chapman, A.; Salova, A.; Rohden, M.; Li, J.; De Badyn, M.H.; Pósfai, M.; Duenas-Osorio, L.; et al. Exotic states in a simple network of nanoelectromechanical oscillators. Science 2019, 363, eaav7932. [CrossRef] [PubMed]

11. Jensen, K.H.; Kim, K.; Zettl, A. An atomic-resolution nanomechanical mass sensor. Nat. Nanotechnol. 2008, 3, 533-537. [CrossRef]

12. Zhang, R.; Chen, W. Recent advances in graphene-based nanomaterials for fabricating electrochemical hydrogen peroxide sensors. Biosens. Bioelectron. 2017, 89, 249-268. [CrossRef]

13. Kumar, R.; Goel, N.; Kumar, M. UV-Activated MoS2 Based Fast and Reversible NO2 Sensor at Room Temperature. ACS Sens. 2017, 2, 1744-1752. [CrossRef]

14. Zhang, Y.; Xie, M.; Roscow, J.; Bao, Y.; Zhou, K.; Zhang, D.; Bowen, C.R. Enhanced pyroelectric and piezoelectric properties of PZT with aligned porosity for energy harvesting applications. J. Mater. Chem. A 2017, 5, 6569-6580. [CrossRef] [PubMed]

15. Elhajjar, R.; Law, C.-T.; Pegoretti, A. Magnetostrictive polymer composites: Recent advances in materials, structures and properties. Prog. Mater. Sci. 2018, 97, 204-229. [CrossRef]

16. Rodrigue, H.; Wang, W.; Kim, D.-R.; Ahn, S.-H. Curved shape memory alloy-based soft actuators and application to soft gripper. Compos. Struct. 2017, 176, 398-406. [CrossRef]

17. Karabalin, R.B.; Matheny, M.H.; Feng, X.L.; Defaÿ, E.; Le Rhun, G.; Marcoux, C.; Hentz, S.; Andreucci, P.; Roukes, M.L. Piezoelectric nanoelectromechanical resonators based on aluminum nitride thin films. Appl. Phys. Lett. 2009, $95,103111$. [CrossRef]

18. Greve, H.; Woltermann, E.; Quenzer, H.-J.; Wagner, B.; Quandt, E. Giant magnetoelectric coefficients in (Fe90Co10)78Si12B10-AlN thin film composites. Appl. Phys. Lett. 2010, 96, 182501. [CrossRef]

19. Xie, X.; Mao, C.; Liu, X.; Tan, L.; Cui, Z.; Yang, X.; Zhu, S.; Li, Z.; Yuan, X.; Zheng, Y.; et al. Tuning the Bandgap of Photo-Sensitive Polydopamine/Ag3PO4/Graphene Oxide Coating for Rapid, Noninvasive Disinfection of Implants. ACS Central Sci. 2018, 4, 724-738. [CrossRef]

20. Yang, Y.; Chen, Y.; Wei, Y.; Li, Y. 3D printing of shape memory polymer for functional part fabrication. Int. J. Adv. Manuf. Technol. 2016, 84, 2079-2095. [CrossRef]

21. Tyc, O.; Heller, L.; Vronka, M.; Šittner, P. Effect of temperature on fatigue of superelastic NiTi wires. Int. J. Fatigue 2020, 134, 105470. [CrossRef] 
22. Crăciunescu, C.; Ercuta, A. Shape memory microactuation design by substrate's reinforcement layers. Mater. Des. 2016, 96, 364-369. [CrossRef]

23. SoltanRezaee, M.; Bodaghi, M. Nonlinear dynamic stability of piezoelectric thermoelastic electromechanical resonators. Sci. Rep. 2020, 10, 1-14. [CrossRef]

24. Singh, J.; Kumar, A.; Chelvane, J.A. Stress compensated MEMS magnetic actuator based on magnetostrictive Fe65Co35 thin films. Sens. Actuators A Phys. 2019, 294, 54-60. [CrossRef]

25. Rivadeneyra, A.; Soto-Rueda, J.M.; O’Keeffe, R.; Banqueri, J.; Jackson, N.; Mathewson, A.; López-Villanueva, J.A. Tunable MEMS piezoelectric energy harvesting device. Microsyst. Technol. 2015, 22, 823-830. [CrossRef]

26. Karaman, I.; Basaran, B.; Karaca, H.E.; Karsilayan, A.I.; Chumlyakov, Y.I. Energy harvesting using martensite variant reorientation mechanism in a NiMnGa magnetic shape memory alloy. Appl. Phys. Lett. 2007, 90, 172505. [CrossRef]

27. Lindquist, P.; Hobza, T.; Patrick, C.; Müllner, P. Efficiency of Energy Harvesting in Ni-Mn-Ga Shape Memory Alloys. Shape Mem. Superelasticity 2018, 4, 93-101. [CrossRef]

28. Morán, M.; Condó, A.; Suarez, S.; Soldera, F.; Haberkorn, N. Ion implantation inducing two-way shape memory effect in $\mathrm{Cu}-\mathrm{Al}-\mathrm{Ni}$ thin films. Mater. Lett. 2019, 255, 126569. [CrossRef]

29. Karim, A.; Guan, C.; Chen, B.; Li, Y.; Zhang, J.; Zhu, L.; Deng, X.; Hu, Y.; Bi, K.; Li, H.; et al. Dynamic observation of Joule heating-induced structural and domain transformation in smart shape-memory alloy. Acta Mater. 2020, 186, 223-228. [CrossRef]

30. Gong, X.; Tan, K.; Deng, Q.; Shen, S. Athermal Shape Memory Effect in Magnetoactive Elastomers. ACS Appl. Mater. Interfaces 2020, 12, 16930-16936. [CrossRef]

31. Sedmák, P.; Pilch, J.; Heller, L.; Kopeček, J.; Wright, J.; Sedlák, P.; Frost, M.; Šittner, P. Grain-resolved analysis of localized deformation in nickel-titanium wire under tensile load. Science 2016, 353, 559-562. [CrossRef] [PubMed]

32. Vallejos, J.M.; Giordana, M.F.; Sobrero, C.E.; Malarria, J.A. Excellent pseudoelasticity of Al-rich Fe-33Mn-17Al-6Ni-0.15C (at \%) shape memory single crystals obtained without an aging conditioning stage. Scr. Mater. 2020, 179, 25-29. [CrossRef]

33. De Sousa, V.C.; Junior, C.D.M. Effect of pseudoelastic hysteresis of shape memory alloy springs on the aeroelastic behavior of a typical airfoil section. J. Intell. Mater. Syst. Struct. 2014, 27, 117-133. [CrossRef]

34. La Roca, P.; Isola, L.; Vermaut, P.; Malarría, J. Relationship between grain size and thermal hysteresis of martensitic transformations in Cu-based shape memory alloys. Scr. Mater. 2017, 135, 5-9. [CrossRef]

35. Heczko, O.; Sozinov, A.; Ullakko, K. Giant field-induced reversible strain in magnetic shape memory NiMnGa alloy. IEEE Trans. Magn. 2000, 36, 3266-3268. [CrossRef]

36. Izadi, M.; Ghafoori, E.; Shahverdi, M.; Motavalli, M.; Maalek, S. Development of an iron-based shape memory alloy (Fe-SMA) strengthening system for steel plates. Eng. Struct. 2018, 174, 433-446. [CrossRef]

37. Šittner, P.; Heller, L.; Pilch, J.; Curfs, C.; Alonso, T.; Favier, D. Young's Modulus of Austenite and Martensite Phases in Superelastic NiTi Wires. J. Mater. Eng. Perform. 2014, 23, 2303-2314. [CrossRef]

38. Kohl, M. Shape Memory Microactuators; Springer: Berlin/Heidelberg, Germany, 2004.

39. Fu, Y.; Du, H.; Huang, W.; Zhang, S.; Hu, M. TiNi-based thin films in MEMS applications: A review. Sens. Actuators A Phys. 2004, 112, 395-408. [CrossRef]

40. Schauer, S.; Worgull, M.; Hölscher, H. Bio-inspired hierarchical micro- and nano-wrinkles obtained via mechanically directed self-assembly on shape-memory polymers. Soft Matter 2017, 13, 4328-4334. [CrossRef]

41. Kirillova, A.; Ionov, L. Shape-changing polymers for biomedical applications. J. Mater. Chem. B 2019, 7, 1597-1624. [CrossRef]

42. Tang, L.; Wen, L.; Xu, S.; Pi, P.-H.; Wen, X. Ca2+, redox, and thermoresponsive supramolecular hydrogel with programmed quadruple shape memory effect. Chem. Commun. 2018, 54, 8084-8087. [CrossRef]

43. Lendlein, A.; Gould, O.E.C. Reprogrammable recovery and actuation behaviour of shape-memory polymers. Nat. Rev. Mater. 2019, 4, 116-133. [CrossRef]

44. Hou, H.; Tang, Y.; Hamilton, R.F.; Horn, M.W. Functional fatigue of submicrometer NiTi shape memory alloy thin films. J. Vac. Sci. Technol. A 2017, 35, 040601. [CrossRef]

45. Liu, B.; Wang, Q.; Hu, S.; Zhang, W.; Du, C. On thermomechanical behaviors of the functional graded shape memory alloy composite for jet engine chevron. J. Intell. Mater. Syst. Struct. 2018, 29, 2986-3005. [CrossRef]

46. Pengzhen, L.; Xiaoli, Z.; Feng, T.; Hua, S. Fundamentals of Shape Memory Alloy-Rubber Bearing Seismic Design and Assessment. J. Mater. Civ. Eng. 2017, 29, 04017081. [CrossRef]

47. Braga, M.T.; Alves, M.T.S.; Cavalini, A.A.; Steffen, V. Influence of temperature on the passive control of a rotating machine using wires of shape memory alloy in the suspension. Smart Mater. Struct. 2020, 29, 035040. [CrossRef]

48. Otsuka, K.; Ren, X. Physical metallurgy of Ti-Ni-based shape memory alloys. Prog. Mater. Sci. 2005, 50, 511-678. [CrossRef]

49. Miyazaki, S.; Fu, Y.Q.; Huang, W.M. Thin Film Shape Memory Alloys: Fundamentals and Device Applications; Cambridge University Press: Cambridge, UK, 2009.

50. Kan, Q.; Yu, C.; Kang, G.; Li, J.; Yan, W. Experimental observations on rate-dependent cyclic deformation of super-elastic NiTi shape memory alloy. Mech. Mater. 2016, 97, 48-58. [CrossRef]

51. Shariat, B.S.; Bakhtiari, S.; Yang, H.; Liu, Y. Controlled initiation and propagation of stress-induced martensitic transformation in functionally graded NiTi. J. Alloys Compd. 2021, 851, 156103. [CrossRef]

52. Atli, K.; Karaman, I.; Noebe, R.D.; Bigelow, G.; Gaydosh, D. Work production using the two-way shape memory effect in NiTi and a Ni-rich NiTiHf high-temperature shape memory alloy. Smart Mater. Struct. 2015, 24, 125023. [CrossRef] 
53. Leu, C.-C.; Vokoun, D.; Hu, C.-T. Two-way shape memory effect of TiNi alloys induced by hydrogenation. Met. Mater. Trans. A 2002, 33, 17-23. [CrossRef]

54. Vokoun, D.; Hu, C. Two-way shape memory effect in Fe-28.8 at. \% Pd melt-spun ribbons. Scr. Mater. 2002, 47, 453-457. [CrossRef]

55. Stachiv, I.; Gan, L. Gan Hybrid Shape Memory Alloy-Based Nanomechanical Resonators for Ultrathin Film Elastic Properties Determination and Heavy Mass Spectrometry. Materials 2019, 12, 3593. [CrossRef] [PubMed]

56. Liu, Y.; Galvin, S. Criteria for pseudoelasticity in near-equiatomic NiTi shape memory alloys. Acta Mater. 1997, 45, 4431-4439. [CrossRef]

57. Tanzi, M.C.; Farè, S.; Candiani, G. Foundations of Biomaterials Engineering; Elsevier BV: Oxford, UK, 2019.

58. Shamimi, A.; Amin-Ahmadi, B.; Stebner, A.; Duerig, T. The Effect of Low Temperature Aging and the Evolution of R-Phase in Ni-Rich NiTi. Shape Mem. Superelasticity 2018, 4, 417-427. [CrossRef]

59. Prokoshkin, S.; Dubinskiy, S.; Brailovski, V.; Korotitskiy, A.; Konopatsky, A.; Sheremetyev, V.; Blinova, E. Nanostructures and stress-induced phase transformation mechanism in titanium nickelide annealed after moderate cold deformation. Mater. Lett. 2017, 192, 111-114. [CrossRef]

60. Ainslie, K.; Knick, C.; Smith, G.; Li, J.; Troxel, C.; Mehta, A.; Kukreja, R. Controlling shape memory effects in NiTi thin films grown on Ru seed layer. Sens. Actuators A Phys. 2019, 294, 133-139. [CrossRef]

61. Zhu, X.; Zhang, X.; Qian, M.; Imran, M. Elastocaloric effects related to B2 $\leftrightarrow$ R and B2 $\leftrightarrow$ B19' martensite transformations in nanocrystalline Ni50.5Ti49.5 microwires. J. Alloys Compd. 2019, 792, 780-788. [CrossRef]

62. Ha, J.-H.; Kim, S.K.; Cohenca, N.; Kim, H.-C. Effect of R-phase Heat Treatment on Torsional Resistance and Cyclic Fatigue Fracture. J. Endod. 2013, 39, 389-393. [CrossRef]

63. Tyc, O.; Pilch, J.; Šittner, P.; Hausild, P. Investigation of the Precipitation Processes in NiTi Filaments. In Proceedings of the International Conference on Martensitic Transformations: Chicago; The Minerals, Metals \& Materials Series; Springer: Cham, Switzerland, 2018; pp. 173-177. [CrossRef]

64. Wang, X.; Kustov, S.; Verlinden, B.E.; Van Humbeeck, J. Fundamental Development on Utilizing the R-phase Transformation in NiTi Shape Memory Alloys. Shape Mem. Superelasticity 2015, 1, 231-239. [CrossRef]

65. Zhao, Q.; Qi, H.J.; Xie, T. Recent progress in shape memory polymer: New behavior, enabling materials, and mechanistic understanding. Prog. Polym. Sci. 2015, 79-120. [CrossRef]

66. Mazurek-Budzinska, M.; Razzaq, M.Y.; Behl, M.; Lendlein, A. Shape-memory polymers. In Functional Polymers; Polymers and Polymeric Composites: A Reference Series; Jafar Mazumder, M.A., Sheardown, H., Al-Ahmed, A., Eds.; Springer International Publishing: Cham, Switzerland, 2019; pp. 605-663.

67. Amir, F.; Liles, K.P.; Delawder, A.O.; Colley, N.D.; Palmquist, M.S.; Linder, H.R.; Sell, S.A.; Barnes, J.C. Reversible Hydrogel Photopatterning: Spatial and Temporal Control over Gel Mechanical Properties Using Visible Light Photoredox Catalysis. ACS Appl. Mater. Interfaces 2019, 11, 24627-24638. [CrossRef]

68. Bhargava, A.; Peng, K.; Stieg, J.; Mirzaeifar, R.; Shahab, S. Focused ultrasound actuation of shape memory polymers; acousticthermoelastic modeling and testing. RSC Adv. 2017, 7, 45452-45469. [CrossRef]

69. Zhang, Y.; Zhou, S.; Chong, K.C.; Wang, S.; Liu, B. Near-infrared light-induced shape memory, self-healable and anti-bacterial elastomers prepared by incorporation of a diketopyrrolopyrrole-based conjugated polymer. Mater. Chem. Front. 2019,3 , 836-841. [CrossRef]

70. Zare, M.; Prabhakaran, M.P.; Parvin, N.; Ramakrishna, S. Thermally-induced two-way shape memory polymers: Mechanisms, structures, and applications. Chem. Eng. J. 2019, 374, 706-720. [CrossRef]

71. Zhang, C.; Gou, X.; Xiao, R. Controllable shape-memory recovery regions in polymers through mechanical programming. J. Appl. Polym. Sci. 2017, 135, 45909. [CrossRef]

72. Xie, T. Tunable polymer multi-shape memory effect. Nat. Cell Biol. 2010, 464, 267-270. [CrossRef]

73. Wu, Y.; Hu, J.; Han, J.; Zhu, Y.; Huang, H.; Li, J.; Tang, B. Two-way shape memory polymer with "switch-spring" composition by interpenetrating polymer network. J. Mater. Chem. A 2014, 2, 18816-18822. [CrossRef]

74. Song, H.; Fang, Z.; Jin, B.; Pan, P.; Zhao, Q.; Xie, T. Synergetic Chemical and Physical Programming for Reversible Shape Memory Effect in a Dynamic Covalent Network with Two Crystalline Phases. ACS Macro Lett. 2019, 8, 682-686. [CrossRef]

75. Wang, K.; Jia, Y.-G.; Zhu, X.X. Two-Way Reversible Shape Memory Polymers Made of Cross-Linked Cocrystallizable Random Copolymers with Tunable Actuation Temperatures. Macromolecules 2017, 50, 8570-8579. [CrossRef]

76. Hui, J.; Xia, H.; Chen, H.; Qiu, Y.; Fu, Y.; Ni, Q.-Q. Two-way reversible shape memory polymer: Synthesis and characterization of benzoyl peroxide-crosslinked poly (ethylene-co-vinyl acetate). Mater. Lett. 2020, 258, 126762. [CrossRef]

77. Wen, Z.; McBride, M.K.; Zhang, X.; Han, X.; Martinez, A.M.; Shao, R.; Zhu, C.; Visvanathan, R.; Clark, N.A.; Wang, Y.; et al. Reconfigurable LC Elastomers: Using a Thermally Programmable Monodomain To Access Two-Way Free-Standing Multiple Shape Memory Polymers. Macromolecules 2018, 51, 5812-5819. [CrossRef]

78. Liu, C.; Qin, H.; Mather, P.T. Review of progress in shape-memory polymers. J. Mater. Chem. 2007, 17, 1543-1558. [CrossRef]

79. Busch, J.D.; Johnson, A.D.; Lee, C.H.; Stevenson, D.A. Shape-memory properties in Ni-Ti sputter-deposited film. J. Appl. Phys. 1990, 68, 6224-6228. [CrossRef]

80. Zuberek, R.; Chumak, O.; Nabiałek, A.; Chojnacki, M.; Radelytskyi, I.; Szymczak, H. Magnetocaloric effect and magnetoelastic properties of NiMnGa and NiMnSn Heusler alloy thin films. J. Alloys Compd. 2018, 748, 1-5. [CrossRef] 
81. Pandey, H.; Rout, P.K.; Anupam Joshi, P.C.; Hossain, Z.; Budhani, R.C. Magnetoelastic coupling induced magnetic anisotropy in Co2 (Fe/Mn)Si thin films. Appl. Phys. Lett. 2014, 104, 022402. [CrossRef]

82. Domenichini, P.; Condó, A.; Soldera, F.; Sirena, M.; Haberkorn, N. Influence of the microstructure on the resulting 18R martensitic transformation of polycrystalline $\mathrm{Cu} \mathrm{Al} \mathrm{Zn}$ thin films obtained by sputtering and reactive annealing. Mater. Charact. 2016, 114, 289-295. [CrossRef]

83. Yang, L.; Tieu, A.; Dunne, D.; Huang, S.; Li, H.; Wexler, D.; Jiang, Z. Cavitation erosion resistance of NiTi thin films produced by Filtered Arc Deposition. Wear 2009, 267, 233-243. [CrossRef]

84. Kauffmann-Weiss, S.; Hahn, S.; Weigelt, C.; Schultz, L.; Wagner, M.-X.; Fähler, S. Growth, microstructure and thermal transformation behaviour of epitaxial Ni-Ti films. Acta Mater. 2017, 132, 255-263. [CrossRef]

85. Hou, H.; Hamilton, R.F.; Horn, M.W.; Jin, Y. NiTi thin films prepared by biased target ion beam deposition co-sputtering from elemental Ni and Ti targets. Thin Solid Films 2014, 570, 1-6. [CrossRef]

86. Musiienko, D.; Straka, L.; Klimša, L.; Saren, A.; Sozinov, A.; Heczko, O.; Ullakko, K. Giant magnetic-field-induced strain in Ni-Mn-Ga micropillars. Scr. Mater. 2018, 150, 173-176. [CrossRef]

87. Li, H.F.; Qiu, K.J.; Zhou, F.Y.; Li, L.; Zheng, Y.F. Design and development of novel antibacterial Ti-Ni-Cu shape memory alloys for biomedical application. Sci. Rep. 2016, 6, 37475. [CrossRef]

88. Bergdahl, G.E.; Andersson, T.; Allhorn, M.; Yngman, S.; Timm, R.; Lood, R. In VivoDetection and Absolute Quantification of a Secreted Bacterial Factor from Skin Using Molecularly Imprinted Polymers in a Surface Plasmon Resonance Biosensor for Improved Diagnostic Abilities. ACS Sensors 2019, 4, 717-725. [CrossRef] [PubMed]

89. Tian, H.; Schryvers, D.; Liu, D.; Jiang, Q.; Van Humbeeck, J. Stability of Ni in nitinol oxide surfaces. Acta Biomater. 2011, 7, 892-899. [CrossRef] [PubMed]

90. McNamara, K.; Beloshapkin, S.; Hossain, K.; Dhoubhadel, M.; Tofail, S. Tantalum coating inhibits Ni-migration from titanium out-diffusion in NiTi shape memory biomedical alloy. Appl. Surf. Sci. 2021, 535, 147621. [CrossRef]

91. Jamesh, M.I.; Li, P.; Bilek, M.M.; Boxman, R.; McKenzie, D.R.; Chu, P.K. Evaluation of corrosion resistance and cytocompatibility of graded metal carbon film on Ti and NiTi prepared by hybrid cathodic arc/glow discharge plasma-assisted chemical vapor deposition. Corros. Sci. 2015, 97, 126-138. [CrossRef]

92. Stanford, N.; Huang, S.; Dunne, D. Characterisation of Ni-Ti thin films produced by filtered arc deposition. Mater. Sci. Eng. A 2008, 473, 172-179. [CrossRef]

93. Boxman, R.L.; Zhitomirsky, V.N. Vacuum arc deposition devices. Rev. Sci. Instruments 2006, 77, 021101. [CrossRef]

94. Wibowo, E.; Kwok, C.Y. Fabrication and characterization of sputtered NiTi shape memory thin films. J. Micromech. Microeng. 2005, 16, 101-108. [CrossRef]

95. Sharma, A.; Mohan, S.; Suwas, S. Development of bi-axial preferred orientation in epitaxial NiMnGa thin films and its consequence on magnetic properties. Acta Mater. 2016, 113, 259-271. [CrossRef]

96. Li, J.; Yi, X.; Meng, X.; Qiao, S.; Cai, W.; Zhao, L. Deposition and phase transformation behaviors of Ti-Ni-Hf-Cu quaternary shape memory alloy thin films. J. Alloys Compd. 2019, 806, 33-39. [CrossRef]

97. Karki, V.; Debnath, A.; Kumar, S.; Bhattacharya, D. Synthesis of co-sputter deposited Ni-Ti thin alloy films and their compositional characterization using depth sensitive techniques. Thin Solid Films 2020, 697, 137800. [CrossRef]

98. Stachiv, I.; Sittner, P.; Olejnicek, J.; Landa, M.; Heller, L. Exploiting NiTi shape memory alloy films in design of tunable high frequency microcantilever resonators. Appl. Phys. Lett. 2017, 111, 213105. [CrossRef]

99. Momeni, S.; Biskupek, J.; Tillmann, W. Tailoring microstructure, mechanical and tribological properties of NiTi thin films by controlling in-situ annealing temperature. Thin Solid Films 2017, 628, 13-21. [CrossRef]

100. Fu, Y.; Du, H.; Zhang, S. Sputtering deposited TiNi films: Relationship among processing, stress evolution and phase transformation behaviors. Surf. Coat. Technol. 2003, 167, 120-128. [CrossRef]

101. Abadias, G.; Chason, E.; Keckes, J.; Sebastiani, M.; Thompson, G.B.; Barthel, E.; Doll, G.; Murray, C.; Stoessel, C.H.; Martinu, L. Review Article: Stress in thin films and coatings: Current status, challenges, and prospects. J. Vac. Sci. Technol. A 2018, $36,020801$. [CrossRef]

102. Wang, X.; Vlassak, J.J. Thickness and film stress effects on the martensitic transformation temperature in equi-atomic NiTi thin films. Mech. Mater. 2015, 88, 50-60. [CrossRef]

103. Juan, J.S.; Nó, M.L.; Schuh, C.A. Superelasticity and Shape Memory in Micro- and Nanometer-scale Pillars. Adv. Mater. 2008, 20, 272-278. [CrossRef]

104. Hou, H.; Horn, M.W.; Hamilton, R.F. Biased Target Ion Beam Deposition and Nanoskiving for Fabricating NiTi Alloy Nanowires. Shape Mem. Superelasticity 2016, 2, 330-336. [CrossRef]

105. Zhang, R.; Wang, S.; Tian, J.; Chen, K.; Xue, P.; Wu, Y.; Chou, W. Effect of PEW and CS on the Thermal, Mechanical, and Shape Memory Properties of UHMWPE. Polymers 2020, 12, 483. [CrossRef] [PubMed]

106. Guo, X.-J.; Xue, C.-H.; Sathasivam, S.; Page, K.; He, G.; Guo, J.; Promdet, P.; Heale, F.L.; Carmalt, C.J.; Parkin, I.P. Fabrication of robust superhydrophobic surfaces via aerosol-assisted CVD and thermo-triggered healing of superhydrophobicity by recovery of roughness structures. J. Mater. Chem. A 2019, 7, 17604-17612. [CrossRef]

107. Zhang, Y.; Huang, L.; Song, H.; Ni, C.; Wu, J.; Zhao, Q.; Xie, T. 4D Printing of a Digital Shape Memory Polymer with Tunable High Performance. ACS Appl. Mater. Interfaces 2019, 11, 32408-32413. [CrossRef] [PubMed]

108. Parameswaranpillai, J.; Siengchin, S.; George, J.J.; Jose, S. Shape Memory Polymers, Blends and Composites; Springer: Singapore, 2020. 
109. Kramer, N.J.; Sachteleben, E.; Ozaydin-Ince, G.; Van De Sanden, R.; Gleason, K.K. Shape Memory Polymer Thin Films Deposited by Initiated Chemical Vapor Deposition. Macromolecules 2010, 43, 8344-8347. [CrossRef]

110. Schröder, S.; Strunskus, T.; Rehders, S.; Gleason, K.K.; Faupel, F. Tunable polytetrafluoroethylene electret films with extraordinary charge stability synthesized by initiated chemical vapor deposition for organic electronics applications. Sci. Rep. $2019,9,2237$. [CrossRef]

111. Alf, M.E.; Asatekin, A.; Barr, M.C.; Baxamusa, S.H.; Chelawat, H.; Ozaydin-Ince, G.; Petruczok, C.D.; Sreenivasan, R.; Tenhaeff, W.E.; Trujillo, N.J.; et al. Chemical Vapor Deposition of Conformal, Functional, and Responsive Polymer Films. Adv. Mater. 2009, 22, 1993-2027. [CrossRef] [PubMed]

112. Gleason, K.K. Nanoscale control by chemically vapour-deposited polymers. Nat. Rev. Phys. 2020, 2, 347-364. [CrossRef]

113. Mao, Y.; Yu, K.; Isakov, M.S.; Wu, J.; Dunn, M.L.; Qi, H.J. Sequential Self-Folding Structures by 3D Printed Digital Shape Memory Polymers. Sci. Rep. 2015, 5, 13616. [CrossRef]

114. Chen, S.; Zhang, Q.; Feng, J. 3D printing of tunable shape memory polymer blends. J. Mater. Chem. C 2017, 5, 8361-8365. [CrossRef]

115. Liu, J.; Zhao, L.; Guo, Y.; Zhang, H.; Zhang, Z. Multi-responsive shape memory polymer printed by fused deposition modeling technique. Express Polym. Lett. 2020, 14, 348-357. [CrossRef]

116. Kuang, X.; Wu, J.; Chen, K.; Zhao, Z.; Ding, Z.; Hu, F.; Fang, D.; Qi, H.J. Grayscale digital light processing 3D printing for highly functionally graded materials. Sci. Adv. 2019, 5, eaav5790. [CrossRef] [PubMed]

117. Choong, Y.Y.C.; Maleksaeedi, S.; Eng, H.; Yu, S.; Wei, J.; Su, P.-C. High speed 4D printing of shape memory polymers with nanosilica. Appl. Mater. Today 2020, 18, 100515. [CrossRef]

118. Ge, Q.; Sakhaei, A.H.; Lee, H.; Dunn, C.K.; Fang, N.X.; Dunn, M.L. Multimaterial 4D Printing with Tailorable Shape Memory Polymers. Sci. Rep. 2016, 6, 31110. [CrossRef] [PubMed]

119. Wei, H.; Zhang, Q.; Yao, Y.; Liu, L.; Liu, Y.; Leng, J. Direct-Write Fabrication of 4D Active Shape-Changing Structures Based on a Shape Memory Polymer and Its Nanocomposite. ACS Appl. Mater. Interfaces 2017, 9, 876-883. [CrossRef]

120. Bodkhe, S.; Ermanni, P. 3D printing of multifunctional materials for sensing and actuation: Merging piezoelectricity with shape memory. Eur. Polym. J. 2020, 132, 109738. [CrossRef]

121. Bártová, B.; Schryvers, D.; Yang, Z.; Ignacova, S.; Šittner, P.; Sedlakova, S. Microstructure and precipitates in as-cast Co38Ni33A129 shape memory alloy. Scr. Mater. 2007, 57, 37-40. [CrossRef]

122. Bae, J.; Lee, H.; Seo, D.; Yun, S.; Yang, J.; Huh, S.; Jeong, H.; Noh, J. Grain Size and Phase Transformation Behavior of TiNi Shape-Memory-Alloy Thin Film under Different Deposition Conditions. Materials 2020, 13, 3229. [CrossRef] [PubMed]

123. Choudhary, N.; Kharat, D.; Kaur, D. Structural, electrical and mechanical properties of magnetron sputtered NiTi/PZT/TiOx thin film heterostructures. Surf. Coat. Technol. 2011, 205, 3387-3396. [CrossRef]

124. Costanza, G.; Paoloni, S.; Tata, M.E. IR Thermography and Resistivity Investigations on Ni-Ti Shape Memory Alloy. Key Eng. Mater. 2014, 605, 23-26. [CrossRef]

125. Thomasová, M.; Sedlák, P.; Seiner, H.; Janovská, M.; Kabla, M.; Shilo, D.; Landa, M. Young's moduli of sputter-deposited NiTi films determined by resonant ultrasound spectroscopy: Austenite, R-phase, and martensite. Scr. Mater. 2015, 101, 24-27. [CrossRef]

126. Konig, D.; Ehmann, M.; Thienhaus, S.; Ludwig, A. Micro- to Nanostructured Devices for the Characterization of Scaling Effects in Shape-Memory Thin Films. J. Microelectromech. Syst. 2010, 19, 1264-1269. [CrossRef]

127. Sedlák, P.; Seiner, H.; Zidek, J.; Janovska, M.; Landa, M. Determination of All 21 Independent Elastic Coefficients of Generally Anisotropic Solids by Resonant Ultrasound Spectroscopy: Benchmark Examples. Exp. Mech. 2014, 54, 1073-1085. [CrossRef]

128. Gao, Y.; Zhao, B.; Vlassak, J.J.; Schick, C. Nanocalorimetry: Door opened for in situ material characterization under extreme non-equilibrium conditions. Prog. Mater. Sci. 2019, 104, 53-137. [CrossRef]

129. Motemani, Y.; McCluskey, P.J.; Zhao, C.; Tan, M. -J.; Vlassak, J.J. Analysis of Ti-Ni-Hf shape memory alloys by combinatorial nanocalorimetry. Acta Mater. 2011, 59, 7602-7614. [CrossRef]

130. McCluskey, P.J.; Xiao, K.; Gregoire, J.M.; Dale, D.; Vlassak, J.J. Application of in-situ nano-scanning calorimetry and X-ray diffraction to characterize Ni-Ti-Hf high-temperature shape memory alloys. Thermochim. Acta 2015, 603, 53-62. [CrossRef]

131. McCluskey, P.J.; Zhao, C.; Kfir, O.; Vlassak, J.J. Precipitation and thermal fatigue in Ni-Ti-Zr shape memory alloy thin films by combinatorial nanocalorimetry. Acta Mater. 2011, 59, 5116-5124. [CrossRef]

132. Meng, X.L.; Sun, B.; Sun, J.Y.; Gao, Z.Y.; Cai, W.; Zhao, L.C. Microstructure and Shape Memory Behavior of Ti-Nb Shape Memory Alloy Thin Film. Shape Mem. Superelasticity 2017, 3, 230-237. [CrossRef]

133. Ossmer, H.; Lambrecht, F.; Gültig, M.; Chluba, C.; Quandt, E.; Kohl, M. Evolution of temperature profiles in TiNi films for elastocaloric cooling. Acta Mater. 2014, 81, 9-20. [CrossRef]

134. Namazu, T.; Hashizume, A.; Inoue, S. Thermomechanical tensile characterization of Ti-Ni shape memory alloy films for design of MEMS actuator. Sens. Actuators A Phys. 2007, 139, 178-186. [CrossRef]

135. Chen, C.-H.; Lu, N.-H. Improved functional stability of Ti-rich TiNi shape memory ribbon prepared by melt-spinning. J. Alloys Compd. 2020, 819, 152988. [CrossRef]

136. Janssen, G.; Abdalla, M.; van Keulen, F.; Pujada, B.; van Venrooy, B. Celebrating the 100th anniversary of the Stoney equation for film stress: Developments from polycrystalline steel strips to single crystal silicon wafers. Thin Solid Films 2009, 517, 1858-1867. [CrossRef] 
137. Knick, C.R.; Smith, G.L.; Morris, C.J.; Bruck, H.A. Rapid and low power laser actuation of sputter-deposited NiTi shape memory alloy (SMA) MEMS thermal bimorph actuators. Sens. Actuators A Phys. 2019, 291, 48-57. [CrossRef]

138. Hou, H.; Hamilton, R.F.; Horn, M.W. Narrow thermal hysteresis of NiTi shape memory alloy thin films with submicrometer thickness. J. Vac. Sci. Technol. A 2016, 34, 050602. [CrossRef]

139. Stachiv, I.; Sittner, P. Nanocantilevers with Adjustable Static Deflection and Significantly Tunable Spectrum Resonant Frequencies for Applications in Nanomechanical Mass Sensors. Nanomaterials 2018, 8, 116. [CrossRef]

140. Fu, Y.; Huang, W.; Du, H.; Huang, X.; Tan, J.; Gao, X. Characterization of TiNi shape-memory alloy thin films for MEMS applications. Surf. Coat. Technol. 2001, 145, 107-112. [CrossRef]

141. Lambrecht, F.; Lay, C.; Aseguinolaza, I.R.; Chernenko, V.; Kohl, M. NiMnGa/Si Shape Memory Bimorph Nanoactuation. Shape Mem. Superelasticity 2016, 2, 347-359. [CrossRef]

142. Kumar, S.; Kumar, I.A.; Marandi, L.; Sen, I. Assessment of small-scale deformation characteristics and stress-strain behavior of NiTi based shape memory alloy using nanoindentation. Acta Mater. 2020, 201, 303-315. [CrossRef]

143. Anuja, J.; Narasimhan, R.; Ramamurty, U.; Jaganathan, A.; Upadrasta, R. Effects of superelasticity and plasticity on the spherical indentation response of shape memory alloys: A finite element analysis. Smart Mater. Struct. 2019, 28, 035028. [CrossRef]

144. Liu, K.; Ostadhassan, M.; Bubach, B.; Dietrich, R.; Rasouli, V. Nano-dynamic mechanical analysis (nano-DMA) of creep behavior of shales: Bakken case study. J. Mater. Sci. 2018, 53, 4417-4432. [CrossRef]

145. Nakamura, N.; Ueno, T.; Ogi, H. Precise control of hydrogen response of semicontinuous palladium film using piezoelectric resonance method. Appl. Phys. Lett. 2019, 114, 201901. [CrossRef]

146. Stachiv, I.; Zapoměl, J.; Chen, Y.-L. Simultaneous determination of the elastic modulus and density/thickness of ultrathin films utilizing micro-/nanoresonators under applied axial force. J. Appl. Phys. 2014, 115, 124304. [CrossRef]

147. Ma, S.; Huang, H.; Lu, M.; Veidt, M. A simple resonant method that can simultaneously measure elastic modulus and density of thin films. Surf. Coat. Technol. 2012, 209, 208-211. [CrossRef]

148. Wang, Q.; Li, X.; Zhao, W.-M.; Jin, S. Lossy mode resonance-based fiber optic sensor using layer-by-layer SnO2 thin film and SnO2 nanoparticles. Appl. Surf. Sci. 2019, 492, 374-381. [CrossRef]

149. Stachiv, I.; Gan, L. Simple Non-Destructive Method of Ultrathin Film Material Properties and Generated Internal Stress Determination Using Microcantilevers Immersed in Air. Coatings 2019, 9, 486. [CrossRef]

150. Segiet, D.; Neuendorf, L.M.; Tiller, J.C.; Katzenberg, F. Realizing a shape-memory effect for synthetic rubber (IR). Polymer 2020, 203, 122788. [CrossRef]

151. Yao, R.; Dong, P.; Liaw, P.K.; Zhou, J.; Wang, W. Microstructure and shape memory effect of laser welded Nitinol wires. Mater. Lett. 2019, 238, 1-5. [CrossRef]

152. Liu, Y.; Gould, O.E.; Rudolph, T.; Fang, L.; Kratz, K.; Lendlein, A. Polymeric Microcuboids Programmable for TemperatureMemory. Macromol. Mater. Eng. 2020, 305, 2000333. [CrossRef]

153. Fang, L.; Gould, O.E.C.; Lysyakova, L.; Jiang, Y.; Sauter, T.; Frank, O.; Becker, T.; Schossig, M.; Kratz, K.; Lendlein, A. Implementing and Quantifying the Shape-Memory Effect of Single Polymeric Micro/Nanowires with an Atomic Force Microscope. ChemPhysChem 2018, 19, 2078-2084. [CrossRef] [PubMed]

154. Fu, Z.; Jiang, L.; Wardini, J.L.; Macdonald, B.E.; Wen, H.; Xiong, W.; Zhang, D.; Zhou, Y.; Rupert, T.J.; Chen, W.; et al. A high-entropy alloy with hierarchical nanoprecipitates and ultrahigh strength. Sci. Adv. 2018, 4, eaat8712. [CrossRef] [PubMed]

155. Liu, Z.; Zeng, H.; Xu, K.; Zhao, K.; Liu, Z.F.; Yao, J.; You, Y.; Wang, D. AFM-IR probing the influence of polarization on the expression of protein within single macrophages. J. Mater. Chem. B 2021. [CrossRef]

156. Stachiv, I.; Gan, L.; Kuo, C.-Y.; Sittner, P.; Sevecek, O. Mass spectrometry of heavy analytes and large biological aggregates by monitoring changes in quality factor of nanomechanical resonator in air. ACS Sens. 2020, 7, 2128-2135. [CrossRef]

157. Lagoudas, D.C.; Entchev, P.B.; Popov, P.; Patoor, E.; Brinson, L.C.; Gao, X. Shape memory alloys, Part II: Modeling of polycrystals Mech. Mater. 2006, 38, 430-462. [CrossRef]

158. Arghavani, J.; Auricchio, F.; Naghdabadi, R.; Reali, A.; Sohrabpour, S. A 3-D phenomenological constitutive model for shape memory alloys under multiaxial loadings. Int. J. Plast. 2010, 26, 976-991. [CrossRef]

159. Luig, P.; Bruhns, O. On the modeling of shape memory alloys using tensorial internal variables. Mater. Sci. Eng. A 2008, 481, 379-383. [CrossRef]

160. Lexcellent, C.; Leclercq, S.; Gabry, B.; Bourbon, G. The two way shape memory effect of shape memory alloys: An experimental study and a phenomenological model. Int. J. Plast. 2000, 16, 1155-1168. [CrossRef]

161. Peng, X.; Chen, B.; Chen, X.; Wang, J.; Wang, H. A constitutive model for transformation, reorientation and plastic deformation of shape memory alloys. Acta Mech. Solida Sin. 2012, 25, 285-298. [CrossRef]

162. Chemisky, Y.; Chatzigeorgiou, G.; Kumar, P.; Lagoudas, D.C. A constitutive model for cyclic actuation of high-temperature shape memory alloys. Mech. Mater. 2014, 68, 120-136. [CrossRef]

163. Hartl, D.J.; Chatzigeorgiou, G.; Lagoudas, D.C. Three-dimensional modeling and numerical analysis of rate-dependent irrecoverable deformation in shape memory alloys. Int. J. Plast. 2010, 26, 1485-1507. [CrossRef]

164. Auricchio, F.; Reali, A.; Stefanelli, U. A three-dimensional model describing stress-induced solid phase transformation with permanent inelasticity. Int. J. Plast. 2007, 23, 207-226. [CrossRef]

165. Sedlák, P.; Frost, M.; Benešová, B.; Ben Zineb, T.; Šittner, P. Thermomechanical model for NiTi-based shape memory alloys including R-phase and material anisotropy under multi-axial loadings. Int. J. Plast. 2012, 39, 132-151. [CrossRef] 
166. Tobushi, H.; Hashimoto, T.; Hayashi, S.; Yamada, E. Thermomechanical Constitutive Modeling in Shape Memory Polymer of Polyurethane Series. J. Intell. Mater. Syst. Struct. 1997, 8, 711-718. [CrossRef]

167. Liu, Y.; Gall, K.; Dunn, M.L.; Greenberg, A.R.; Diani, J. Thermomechanics of shape memory polymers: Uniaxial experiments and constitutive modeling. Int. J. Plast. 2006, 22, 279-313. [CrossRef]

168. Li, Y.; Hu, J.; Liu, Z. A constitutive model of shape memory polymers based on glass transition and the concept of frozen strain release rate. Int. J. Solids Struct. 2017, 124, 252-263. [CrossRef]

169. Li, Y.; Liu, Z. A novel constitutive model of shape memory polymers combining phase transition and viscoelasticity. Polymer 2018, 143, 298-308. [CrossRef]

170. Yarali, E.; Baniasadi, M.; Bodaghi, M.; Baghani, M. 3D constitutive modeling of electro-magneto-visco-hyperelastic elastomers: A semi-analytical solution for cylinders under large torsion-extension deformation. Smart Mater. Struct. 2020, $29,085031$. [CrossRef]

171. Bonner, M.; De Oca, H.M.; Brown, M.; Ward, I. A novel approach to predict the recovery time of shape memory polymers. Polymer 2010, 51, 1432-1436. [CrossRef]

172. Baghani, M.; Naghdabadi, R.; Arghavani, J.; Sohrabpour, S. A thermodynamically-consistent 3D constitutive model for shape memory polymers. Int. J. Plast. 2012, 35, 13-30. [CrossRef]

173. Diani, J.; Gilormini, P.; Frédy, C.; A Rousseau, I. Predicting thermal shape memory of crosslinked polymer networks from linear viscoelasticity. Int. J. Solids Struct. 2012, 49, 793-799. [CrossRef]

174. Baniasadi, M.; Foyouzat, A.; Baghani, M. Multiple Shape Memory Effect for Smart Helical Springs with Variable Stiffness over Time and Temperature. Int. J. Mech. Sci. 2020, 182, 105742. [CrossRef]

175. Patriarca, L.; Sehitoglu, H.; Panchenko, E.Y.; Chumlyakov, Y. High-temperature functional behavior of single crystal Ni51.2Ti23.4Hf25.4 shape memory alloy. Acta Mater. 2016, 106, 333-343. [CrossRef]

176. Alarcon, E.; Heller, L. Deformation infrared calorimetry for materials characterization applied to study cyclic superelasticity in NiTi wires. Mater. Des. 2021, 199, 109406. [CrossRef]

177. Yu, H.; Young, M.L. Effect of temperature on high strain rate deformation of austenitic shape memory alloys by phenomenological modeling. J. Alloys Compd. 2019, 797, 194-204. [CrossRef]

178. Zhuo, M. Timescale competition dictates thermo-mechanical responses of NiTi shape memory alloy bars. Int. J. Solids Struct. 2020, 193-194, 601-617. [CrossRef]

179. Shaw, J.A. Simulations of localized thermo-mechanical behavior in a NiTi shape memory alloy. Int. J. Plast. 2000, 16, 541-562. [CrossRef]

180. Wendler, F.; Ossmer, H.; Chluba, C.; Quandt, E.; Kohl, M. Mesoscale simulation of elastocaloric cooling in SMA films. Acta Mater. 2017, 136, 105-117. [CrossRef]

181. Duval, A.; Haboussi, M.; Ben Zineb, T. Modelling of localization and propagation of phase transformation in superelastic SMA by a gradient nonlocal approach. Int. J. Solids Struct. 2011, 48, 1879-1893. [CrossRef]

182. Frost, M.; Benešová, B.; Seiner, H.; Kružík, M.; Šittner, P.; Sedlák, P. Thermomechanical model for NiTi-based shape memory alloys covering macroscopic localization of martensitic transformation. Int. J. Solids Struct. 2020, in press. [CrossRef]

183. Jiang, D.; Kyriakides, S.; Bechle, N.J.; Landis, C.M. Bending of pseudoelastic NiTi tubes. Int. J. Solids Struct. 2017, 124, 192-214. [CrossRef]

184. Kim, Y.-J.; Lee, C.-H.; Kim, J.-H.; Lim, J.H. Numerical modeling of shape memory alloy plates considering tension/compression asymmetry and its verification under pure bending. Int. J. Solids Struct. 2018, 77-88. [CrossRef]

185. Zaki, W.; Moumni, Z.; Morin, C. Modeling Tensile-Compressive Asymmetry for Superelastic Shape Memory Alloys. Mech. Adv. Mater. Struct. 2011, 18, 559-564. [CrossRef]

186. Bechle, N.J.; Kyriakides, S. Evolution of phase transformation fronts and associated thermal effects in a NiTi tube under a biaxial stress state. Extreme Mech. Lett. 2016, 8, 55-63. [CrossRef]

187. Damanpack, A.; Bodaghi, M.; Liao, W. A finite-strain constitutive model for anisotropic shape memory alloys. Mech. Mater. 2017, 112, 129-142. [CrossRef]

188. Šittner, P.; Sedlák, P.; Seiner, H.; Sedmák, P.; Pilch, J.; Delville, R.; Heller, L.; Kadeřávek, L. On the coupling between martensitic transformation and plasticity in NiTi: Experiments and continuum based modelling. Prog. Mater. Sci. 2018, 98, 249-298. [CrossRef]

189. Oliveira, S.D.A.; Dornelas, V.M.; Savi, M.A.; Pacheco, P.M.C.L.; Paiva, A. A phenomenological description of shape memory alloy transformation induced plasticity. Meccanica 2018, 53, 2503-2523. [CrossRef]

190. Merzouki, T.; Duval, A.; Ben Zineb, T. Finite Element analysis of a shape memory alloy actuator for a micropump. Simul. Model. Pr. Theory 2012, 27, 112-126. [CrossRef]

191. Pan, Q.; Cho, C. The Investigation of a Shape Memory Alloy Micro-Damper for MEMS Applications. Sensors 2007, 7, 1887-1900. [CrossRef] [PubMed]

192. Lee, H.-T.; Kim, M.-S.; Lee, G.-Y.; Kim, C.-S.; Ahn, S.-H. Shape Memory Alloy (SMA)-Based Microscale Actuators with 60\% Deformation Rate and $1.6 \mathrm{kHz}$ Actuation Speed. Small 2018, 14, e1801023. [CrossRef] [PubMed]

193. AbuZaiter, A.; Nafea, M.; Ali, M.S.S.M. Development of a shape-memory-alloy micromanipulator based on integrated bimorph microactuators. Mechatronics 2016, 38, 16-28. [CrossRef] 
194. Jiang, D.; Xiao, Y. Modelling on grain size dependent thermomechanical response of superelastic NiTi shape memory alloy. Int. J. Solids Struct. 2021, 210-211, 170-182. [CrossRef]

195. Yu, C.; Kang, G.; Xie, X.; Rao, W. A micromechanical model for the grain size dependent super-elasticity degeneration of NiTi shape memory alloys. Mech. Mater. 2018, 125, 35-51. [CrossRef]

196. Li, M.; Sun, Q. Nanoscale phase transition behavior of shape memory alloys-closed form solution of 1D effective modelling. J. Mech. Phys. Solids 2018, 110, 21-37. [CrossRef]

197. Heller, L.; Karafítov, I.; Petrich, L.; Pawlas, Z.; Shayanfard, P.; Benes, V.; Schmidt, V.; Sittner, P.; Karafiatova, I. Numerical microstructure model of NiTi wire reconstructed from 3D-XRD data. Model. Simul. Mater. Sci. Eng. 2020, 28, 055007. [CrossRef]

198. Kafka, V. Shape memory polymers: A mesoscale model of the internal mechanism leading to the SM phenomena. Int. J. Plast. 2008, 24, 1533-1548. [CrossRef]

199. Maurel, G.; Schnell, B.; Goujon, F.; Couty, M.; Malfreyt, P. Multiscale Modeling Approach toward the Prediction of Viscoelastic Properties of Polymers. J. Chem. Theory Comput. 2012, 8, 4570-4579. [CrossRef]

200. Uddin, S.; Ju, J. Enhanced Coarse-Graining of Thermoplastic Polyurethane Elastomer for Multiscale Modeling. J. Eng. Mater. Technol. 2016, 139, 011001. [CrossRef]

201. Park, S.; Moon, J.; Kim, B.; Cho, M. Multi-scale coarse-grained molecular dynamics simulation to investigate the thermomechanical behavior of shape-memory polyurethane copolymers. Polymer 2021, 213, 123228. [CrossRef]

202. Zhong, Y.; Gall, K.; Zhu, T. Atomistic characterization of pseudoelasticity and shape memory in NiTi nanopillars. Acta Mater. 2012, 60, 6301-6311. [CrossRef]

203. Ko, W.-S.; Grabowski, B.; Neugebauer, J. Development and application of a Ni-Ti interatomic potential with high predictive accuracy of the martensitic phase transition. Phys. Rev. B 2015, 92, 134107. [CrossRef]

204. Diani, J.; Gall, K. Molecular dynamics simulations of the shape-memory behaviour of polyisoprene. Smart Mater. Struct. 2007, 16, 1575-1583. [CrossRef]

205. Wang, M.; Jiang, S.; Zhang, Y. Phase Transformation, Twinning, and Detwinning of NiTi Shape-Memory Alloy Subject to a Shock Wave Based on Molecular-Dynamics Simulation. Materials 2018, 11, 2334. [CrossRef] [PubMed]

206. Lv, C.; Zhang, X.P.; Wang, G.J.; Zhao, F.; Luo, N.; Bland, S.N.; Tan, F.L.; Zhao, J.H.; Liu, C.L.; Sun, C.W. Twinning and rotational deformation of nanocrystalline NiTi under shock loading. Phys. Rev. Mater. 2020, 4, 093607. [CrossRef]

207. Wang, B.; Kang, G.; Kan, Q.; Zhou, K.; Yu, C. Molecular dynamics simulations to the pseudo-elasticity of NiTi shape memory alloy nano-pillar subjected to cyclic compression. Comput. Mater. Sci. 2017, 131, 132-138. [CrossRef]

208. Chen, X.; Chen, W.; Ma, Y.; Zhao, Y.; Deng, C.; Peng, X.; Fu, T. Tension-Compression asymmetry of single-crystalline and nanocrystalline NiTi shape memory alloy: An atomic scale study. Mech. Mater. 2020, 145, 103402. [CrossRef]

209. Sun, Y.; Luo, J.; Zhu, J. Phase field study of the microstructure evolution and thermomechanical properties of polycrystalline shape memory alloys: Grain size effect and rate effect. Comput. Mater. Sci. 2018, 145, 252-262. [CrossRef]

210. Ko, W.-S.; Choi, W.S.; Xu, G.; Choi, P.-P.; Ikeda, Y.; Grabowski, B. Dissecting functional degradation in NiTi shape memory alloys containing amorphous regions via atomistic simulations. Acta Mater. 2021, 202, 331-349. [CrossRef]

211. Wang, B.; Kang, G.; Wu, W.; Zhou, K.; Kan, Q.; Yu, C. Molecular dynamics simulations on nanocrystalline super-elastic NiTi shape memory alloy by addressing transformation ratchetting and its atomic mechanism. Int. J. Plast. 2020, 125, 374-394. [CrossRef]

212. Gur, S.; Frantziskonis, G.N.; Muralidharan, K. Atomistic simulation of shape memory effect (SME) and superelasticity (SE) in nano-porous NiTi shape memory alloy (SMA). Comput. Mater. Sci. 2018, 152, 28-37. [CrossRef]

213. Wick, C.D.; Peters, A.J.; Li, G. Quantifying the contributions of energy storage in a thermoset shape memory polymer with high stress recovery: A molecular dynamics study. Polymer 2021, 213, 123319. [CrossRef]

214. Zhang, X.-J.; Yang, Q.-S.; Liu, X.; Shang, J.-J.; Leng, J.-S. Atomistic investigation of the shape-memory effect of amorphous poly(L-lactide) with different molecular weights. Smart Mater. Struct. 2019, 29, 015040. [CrossRef]

215. Shu, Y.-C. Shape-Memory Micropumps. Mater. Trans. 2002, 43, 1037-1044. [CrossRef]

216. Knick, C.R.; Sharar, D.J.; A Wilson, A.; Smith, G.L.; Morris, C.J.; A Bruck, H. High frequency, low power, electrically actuated shape memory alloy MEMS bimorph thermal actuators. J. Micromech. Microeng. 2019, 29, 075005. [CrossRef]

217. Singh, S.; Subramaniam, K.; Chittora, N.; Brolin, A.; Palani, I. Studies on development of NiTi-integrated optical fiber sensor and its life cycle behavior. J. Intell. Mater. Syst. Struct. 2020, 31, 869-881. [CrossRef]

218. Askari-Naeini, F.G.; Taghizadeh, M.; Mohri, M.; Nili-Ahmadabadi, M. On the microstructure and mechanical properties of a two-way shape memory NiTi/NiTiCu bi-layer diaphragm. Mater. Des. 2020, 188, 108464. [CrossRef]

219. Robertson, J.M.; Rodriguez, R.X.; Holmes, L.R.; Mather, P.T.; Wetzel, E.D. Thermally driven microfluidic pumping via reversible shape memory polymers. Smart Mater. Struct. 2016, 25, 085043. [CrossRef]

220. Kabla, M.; Ben-David, E.; Shilo, D. A novel shape memory alloy microactuator for large in-plane strokes and forces. Smart Mater. Struct. 2016, 25, 75020. [CrossRef]

221. AbuZaiter, A.; Nafea, M.; Faudzi, A.A.M.; Kazi, S.; Ali, M.S.M. Thermomechanical behavior of bulk NiTi shape-memory-alloy microactuators based on bimorph actuation. Microsyst. Technol. 2015, 22, 2125-2131. [CrossRef]

222. Shelyakov, A.; Sitnikov, N.; Borodako, K.; Koledov, V.; Khabibullina, I.; Von Gratowski, S. Design of microgrippers based on amorphous-crystalline TiNiCu alloy with two-way shape memory. J. Micro-Bio Robot. 2020, 16, 43-51. [CrossRef]

223. Xiong, F.; Yang, H.; Liu, K.; Man, J.; Chen, H. Forming and two-way shape memory effect of NiTi alloy induced by laser shock imprinting. Opt. Laser Technol. 2019, 120, 105762. [CrossRef] 
224. Song, S.-H.; Lee, J.-Y.; Rodrigue, H.; Choi, I.-S.; Kang, Y.J.; Ahn, S.-H. 35 Hz shape memory alloy actuator with bending-twisting mode. Sci. Rep. 2016, 6, 21118. [CrossRef]

225. Stachiv, I.; Sittner, P.; Jeng, Y.R.; Vokoun, D. Active frequency tuning of the cantilever nanoresonator utilizing a phase transformation of NiTi thin film. J. Vibroeng. 2017, 19, 5161-5169. [CrossRef]

226. Kohl, M.; Gueltig, M.; Pinneker, V.; Yin, R.; Wendler, F.; Krevet, B. Magnetic Shape Memory Microactuators. Micromachines 2014, 5, 1135-1160. [CrossRef]

227. Qingxin, Z.; Qihang, F.; Luping, W.; Yunhong, G. Research and Experimental Analysis of Damping Characteristics of Magnetic Shape Memory Alloy. Trans. Electr. Electron. Mater. 2018, 19, 272-278. [CrossRef]

228. Yu, Y.; Zhang, C.; Zhou, M. NARMAX Model-Based Hysteresis Modeling of Magnetic Shape Memory Alloy Actuators. IEEE Trans. Nanotechnol. 2020, 19, 1-4. [CrossRef]

229. Zhang, C.; Yu, Y.; Wang, Y.; Zhou, M. Takagi-Sugeno Fuzzy Neural Network Hysteresis Modeling for Magnetic Shape Memory Alloy Actuator Based on Modified Bacteria Foraging Algorithm. Int. J. Fuzzy Syst. 2020, 22, 1314-1329. [CrossRef]

230. Zhao, W.; Liu, L.; Zhang, F.; Leng, J.; Liu, Y. Shape memory polymers and their composites in biomedical applications. Mater. Sci. Eng. C 2019, 97, 864-883. [CrossRef] [PubMed]

231. Liu, X.; Pan, X.; Debije, M.G.; Heuts, J.P.A.; Mulder, D.-J.; Schenning, A.P.H.J. Programmable liquid crystal elastomer microactuators prepared via thiol-ene dispersion polymerization. Soft Matter 2020, 16, 4908-4911. [CrossRef] [PubMed]

232. Zainal, M.A.; Ahmad, A.; Ali, M.S.M. Frequency-controlled wireless shape memory polymer microactuator for drug delivery application. Biomed. Microdevices. 2017, 19, 8. [CrossRef]

233. De Marco, C.; Alcântara, C.C.J.; Kim, S.; Briatico, F.; Kadioglu, A.; De Bernardis, G.; Chen, X.; Marano, C.; Nelson, B.J.; Pané, S. Indirect 3D and 4D Printing of Soft Robotic Microstructures. Adv. Mater. Technol. 2019, 4. [CrossRef]

234. Georgopoulou, A.; Michel, S.; VanderBorght, B.; Clemens, F. Piezoresistive sensor fiber composites based on silicone elastomers for the monitoring of the position of a robot arm. Sens. Actuators A Phys. 2021, 318, 112433. [CrossRef]

235. Farhan, M.; Rudolph, T.; Nöchel, U.; Yan, W.; Kratz, K.; Lendlein, A. Noncontinuously Responding Polymeric Actuators. ACS Appl. Mater. Interfaces 2017, 9, 33559-33564. [CrossRef]

236. Alian, A.; Meguid, S. Multiscale modeling of the coupled electromechanical behavior of multifunctional nanocomposites. Compos. Struct. 2019, 208, 826-835. [CrossRef] 